\title{
Methacryloyl-GlcNAc Derivatives Copolymerized with Dimethacrylamide as a Novel Antibacterial and Biocompatible Coating
}

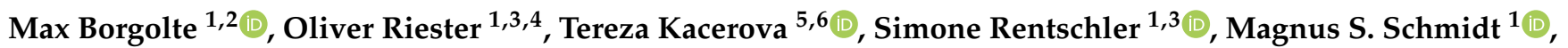 \\ Susanne Jacksch ${ }^{1}\left(\mathbb{D}\right.$, Markus Egert ${ }^{1}\left(\mathbb{D}\right.$, Stefan Laufer ${ }^{3,4}{ }^{(D)}$, René Csuk ${ }^{2} \mathbb{D}$ and Hans-Peter Deigner ${ }^{1,4,7, *(\mathbb{D})}$ \\ 1 Institute of Precision Medicine, Furtwangen University, Jakob-Kienzle Str. 17, \\ 78054 Villingen-Schwenningen, Germany; Max.Borgolte@hs-furtwangen.de (M.B.); \\ Oliver.Riester@hs-furtwangen.de (O.R.); S.Rentschler@hs-furtwangen.de (S.R.); \\ Magnus.Schmidt@hs-furtwangen.de (M.S.S.); Susanne.Jacksch@hs-furtwangen.de (S.J.); \\ Markus.Egert@hs-furtwangen.de (M.E.) \\ 2 Department of Organic Chemistry, Martin-Luther University Halle-Wittenberg, Kurt-Mothes Str. 2, \\ 06120 Halle (Saale), Germany; Rene.csuk@chemie.uni-halle.de \\ 3 Department of Pharmaceutical and Medicinal Chemistry, Institute of Pharmaceutical Sciences, \\ Eberhard Karls University Tuebingen, Auf der Morgenstelle 8, 72076 Tübingen, Germany; \\ Stefan.laufer@uni-tuebingen.de \\ check for \\ updates \\ Citation: Borgolte, M.; Riester, O.; \\ Kacerova, T.; Rentschler, S.; \\ Schmidt, M.S.; Jacksch, S.; Egert, M.; \\ Laufer, S.; Csuk, R.; Deigner, H.-P. \\ 4 Faculty of Science, Eberhard Karls University Tuebingen, Auf der Morgenstelle 8, 72076 Tübingen, Germany \\ 5 Department of Chemistry, Czech University of Life Sciences, Kamýcká 129, 16500 Prague, Czech Republic; \\ tereza.kacerova.18@ucl.ac.uk \\ 6 Department of Chemistry, University College London, London WC1H 0AJ, UK \\ 7 EXIM Department, Fraunhofer Institute IZI (Leipzig), Schillingallee 68, 18057 Rostock, Germany \\ * Correspondence: dei@hs-furtwangen.de
} Methacryloyl-GlcNAc Derivatives Copolymerized with

Dimethacrylamide as a Novel Antibacterial and Biocompatible Coating. Pharmaceutics 2021, 13, 1647. https://doi.org/10.3390/ pharmaceutics13101647

Academic Editors: Ewa Kłodzińska; and Marek Konop

Received: 3 August 2021

Accepted: 2 October 2021

Published: 9 October 2021

Publisher's Note: MDPI stays neutral with regard to jurisdictional claims in published maps and institutional affiliations.

Copyright: (C) 2021 by the authors. Licensee MDPI, Basel, Switzerland. This article is an open access article distributed under the terms and conditions of the Creative Commons Attribution (CC BY) license (https:// creativecommons.org/licenses/by/ $4.0 /)$

\begin{abstract}
Improving medical implants with functional polymer coatings is an effective way to further improve the level of medical care. Antibacterial and biofilm-preventing properties are particularly desirable in the area of wound healing, since there is a generally high risk of infection, often with a chronic course in the case of biofilm formation. To prevent this we here report a polymeric design of polymer-bound $\mathrm{N}$-acetyl-glucosamine-oligoethylene glycol residues that mimic a cationic, antibacterial, and biocompatible chitosan surface. The combination of easy to use, crosslinkable, thin, potentially 3D-printable polymethacrylate layering with antibacterial and biocompatible functional components will be particularly advantageous in the medical field to support a wide range of implants as well as wound dressings. Different polymers containing a $\mathrm{N}$-acetylglucosaminemethacryloyl residue with oligoethylene glycol linkers and a methacryloyl benzophenone crosslinker were synthesized by free radical polymerization. The functional monomers and corresponding polymers were characterized by ${ }^{1} \mathrm{H},{ }^{13} \mathrm{C} N \mathrm{NM}$, and infrared (IR) spectroscopy. The polymers showed no cytotoxic or antiadhesive effects on fibroblasts as demonstrated by extract and direct contact cell culture methods. Biofilm formation was reduced by up to $70 \%$ and antibacterial growth by $1.2 \log$, particularly for the 5\% GlcNAc-4EG polymer, as observed for Escherichia coli and Staphylococcus aureus as clinically relevant Gram-negative and Gram-positive model pathogens.
\end{abstract}

Keywords: carbohydrates; glycosides; antibacterial; antibiofilm; MRSA; E. coli; biocompatible

\section{Introduction}

Bacterial wound infections are a major health problem, comparable to infections subsequent to surgical procedures, especially when a biofilm is formed significantly reducing the susceptibility of bacteria to antibiotics [1-3]. In combination with the increasing number of reported multidrug-resistant pathogens, antibiotic resistant bacterial infections are a clinical problem that will become even more acute in the future [4]. An implant or scaffold has to be functional for fibroblast or stem cells adhesion to ensure proper resorption of 
the implant into the surrounding tissue. This functionalization promotes adhesion often unspecifically for all cells and organisms, including bacteria, leading to a "race to the surface" $[5,6]$, whereby the patient's cells and bacteria compete to adhere to an implant's surface. The critical time window for this competition between body tissue and bacteria has been determined to be the first $6 \mathrm{~h}$ after implantation, while a single bacteria can form a biofilm within $24 \mathrm{~h}$ [7]. After $48-96 \mathrm{~h}$, the biofilm becomes resistant to therapeutic treatment as the formed matrix renders the encapsulated bacteria less susceptible to host defense mechanisms and antibiotic therapy [8-12]. Conventionally, antibiotic prophylaxis is used in both implant surgery and traumatic wound care to reduce the likelihood of bacterial infections $[13,14]$. However, the problem of increasing multidrug-resistant bacteria, particularly in clinical settings, has led to a re-evaluation of the extensive use of antibiotics $[15,16]$. To some degree, reducing the usage of systemic antibiotics can prevent the emergence of new multidrug-resistant pathogens. In order to prevent infections even with reduced administration of antibiotics, other antimicrobial mechanisms must also be applied, such as antimicrobial modification of surfaces or addition of nanoparticles [17-19].

Cationic polymers have been widely described in articles and reviews with regard to their antibacterial properties and use in self-disinfecting surfaces; most contain a quaternary ammonium group or alkyl pyridinium group as the functional component [20-25]. The mechanism of action of these cationic polymers in solution is well described by the Shai-Matsuzaki-Huang (SMH) model [26-28]. The antibacterial action of surfaces coated with cationic polymers is thought to follow a similar mechanism through polymeric brushes [21,29-33], but some publications describe a simple monolayer of cationic groups as being antibacterial as well [34]. Murata et al. propose a mechanism driven mainly by surface charge instead of insertion of cationic polymer brushes into the bacterial cell wall, following an SMH-like mechanism [20]. The exact mechanism of the antibacterial effect of cationic polymers requires further discussion and clarification.

Chitosan is a cationic polymeric aminoglycan, consisting of $\mathrm{N}$-acetylglucosamine (GlcNAc) and glucosamine repeating units; it is used in tissue engineering applications such as bone tissue engineering [35-37], stem cell encapsulation [38-40], and wound dressing $[41,42]$. The polymer is thought to exhibit its antibacterial properties through a cationic mechanism via glucosamine's amino group by disrupting the outer and inner bacterial cell membrane [43-45] and has been shown to mediate biofilm formation of Actinobacillus pleuromoniae [46]. The corresponding monomer, GlcNAc, has been shown to prevent biofilm formation by Escherichia coli [47]. Because of its insolubility in water and organic solvents, except ionic liquids, chitosan has been used in several polymeric modifications to combine its proliferative and antibacterial properties with the mechanical stiffness of other polymers, taking advantage of different synthetic polymers or nanoparticles, rendering it useful for biomedical applications [48].

Another group of antimicrobial compounds is the 1,2,3-triazoles, which exhibit antibacterial activity mainly through formation of hydrogen bonds of the triazole ring with other moieties, forming a cationic surface and possibly leading to an SMH-like antibacterial mechanism [49]. These 1,2,3-triazoles can easily be introduced by Huisgen 1,3-dipolar cycloaddition of an azide and alkyne, without the need for complicated workup procedures or toxic and expensive reagents, making it suitable for polymer modifications [50,51]. Several polymers modified in this way are listed in a library of (1,2,3-triazol-1-yl)quinazolin4-ones and have shown antibacterial properties against Gram-positive and Gram-negative bacteria [52,53]. In addition, a library of 1,2,3-triazol-sucrose derivatives showed antifungal and antibacterial properties while maintaining low cytotoxicity against non-tumor cell lines [54-56].

An additional approach is the design of antiadhesive surfaces to prevent colonization of implant surfaces. Pandiyarajan et al. [57] described a surface-attached hydrogel network, consisting of poly-dimethacrylamide copolymerized with methacryloyl benzophenone (MBP), that had antiadhesive properties against proteins and blood platelets. Surface anchoring was accomplished via photoactive UV crosslinking of the benzophenone moi- 
ety [57]. The benzophenone undergoes a UV-induced, radical C-H insertion reaction, as reviewed by Prucker et al. [58] rendering it suitable for functionalization of polymeric surfaces to obtain stable, covalently attached hydrogel networks [58]. To the best of our knowledge, there is no description of combining the antimicrobial properties of a cationic GlcNAc residue with an antiadhesive, UV-crosslinkable acrylamide hydrogel in order to reduce microbial contamination of implant surfaces in the literature.

In this study, we combined the previously described approaches that resulted in a surface-bound poly-dimethacrylamide methyl (PDMAm) network with UV-induced anchoring via benzophenone, combining it with a GlcNAc residue containing a triazole and a distinct linker to the PDMAm network backbone. We thereby mimicked an antimicrobial chitosan surface while taking advantage of the antiadhesive PDMAm hydrogel as base layer. The hydrogel network can be easily obtained via solvent casting of the polymer solution, followed by UV crosslinking. We investigated the effect of the combinatorial approach of triazole functional groups and chitosan-mimicking surfaces on the antimicrobial, antibiofilm, and biocompatible properties of such coatings.

\section{Experimental Section}

2.1. Chemical Synthesis and Characterization

\subsubsection{General Methods}

TLC was carried out on Silica Gel 60 F254 (Merck KGaA, Darmstadt, Germany, layer thickness $0.2 \mathrm{~mm}$ ) with detection by UV light $(254 \mathrm{~nm})$ or by charring with $1 \% \mathrm{KMnO}_{4}$ in $1 \mathrm{~N} \mathrm{NaOH}$. Flash column chromatography (FC) was performed on M\&N Silica Gel 60 (0.063-0.200 mm, MACHEREY-NAGEL GmbH, Düren, Germany). ${ }^{1} \mathrm{H}$ NMR and ${ }^{13} \mathrm{C}$ NMR spectra were recorded on a Bruker Avance I 200, Bruker Avance II 400 (Bruker Corporation, Billerica, MA, USA), or Varian Unity 500 (Varian, Palo Alto, CA, USA) spectrometer. Chemical shifts are reported in parts per million relative to solvent signals $\left(\mathrm{CDCl}_{3}: \delta \mathrm{H}=7.26 \mathrm{ppm}, \delta \mathrm{C}=77.0 \mathrm{ppm}\right.$; DMSO-d6: $\delta \mathrm{H}=2.49 \mathrm{ppm}, \delta \mathrm{C}=39.7 \mathrm{ppm} ; \mathrm{CD}_{3} \mathrm{OD}$ : $\delta \mathrm{H}=4.78 \mathrm{ppm}, \delta \mathrm{C}=49.3 \mathrm{ppm})$. Signals were assigned by first-order analysis, and assignments were supported, where feasible, by 2-dimensional ${ }^{1} \mathrm{H},{ }^{1} \mathrm{H}$ and ${ }^{1} \mathrm{H},{ }^{13} \mathrm{C}$ correlation spectroscopy. Coupling constants are reported in hertz. Chemicals and reagents were purchased from Acros Organics (Geel, Belgium), Sigma-Aldrich (Munich, Germany), Carl Roth (Karlsruhe, Germany), ABCR (Karlsruhe, Germany), or MCAT (Donaueschingen, Germany) and were used without further purification.

\subsubsection{Synthesis of Azido Linkers 2, 4, 5, 6}

Azido linkers were synthesized according to a procedure published by Mahou and Wandrey [59], following a cascade of sequential tosylation and $\mathrm{NaN}_{3}$ substitution steps. For diethylene glycol linker 2, 2-(2-chloro-ethoxy)-ethanol was chosen as the starting material instead of the tosylated diethylene glycol residue, according to another published procedure [60].

\subsubsection{General Tosylation Procedure}

Tosylation was carried out according to a literature report [59]. The corresponding linker (1 eq) and $p$-toluenesulfonyl chloride (1.1 eq) were dissolved in dichloromethane (DCM) at $0{ }^{\circ} \mathrm{C}$ and $\mathrm{NEt}_{3}$ (2 eq) was added. After stirring for $2 \mathrm{~h}$, the ice bath was removed and the mixture stirred overnight at room temperature. Washing twice with water and once with brine, followed by evaporation of the solvent, yielded the tosylated linker as a yellowish oil.

\subsubsection{Chain Prolongment of Azido Linkers via Tosylate 5, 6}

Chain prolongment was carried out according to the literature [59]. Tosylated azido linker 4 (1 eq) and $\mathrm{NaH}$ (1.1 eq) were suspended in water-free tetrahydrofuran (THF) under Ar atmosphere. After stirring for $30 \mathrm{~min}$ at room temperature, diethylene glycol for product 5 or 1,8-octanediol for product 6 ( 5 eq) was added dropwise to the mixture. After 
stirring for $48 \mathrm{~h}$ under reflux, $\mathrm{H}_{2} \mathrm{O}$ was added, the solvent evaporated, and the aqueous layer extracted $3 \times$ with DCM Washing $2 \times$ with $\mathrm{NaOH}$, followed by evaporation of the solvent and column chromatography (ethyl acetate/methanol 19:1, $R_{f}=0.4$ ), yielded the pure products 5 and $\mathbf{6}$ as yellowish oils.

8-(2-\{2-[2-(2-Azido-ethoxy)-ethoxy]-ethoxy\}-ethoxy)-octan-1-ol 6

Yield: $71 \%$

${ }^{1} \mathrm{H}-\mathrm{NMR}\left(\mathrm{CDCl}_{3}, 400 \mathrm{MHz}\right): 3.71-3.63\left(\mathrm{~m}, 14 \mathrm{H}, \mathrm{O}-\mathrm{CH}_{2}\right), 3.59(\mathrm{dt}, J=4.5,1.2 \mathrm{~Hz}, 2 \mathrm{H}$, $\left.\mathrm{O}-\mathrm{CH}_{2}\right), 3.46\left(\mathrm{t}, J=6.8 \mathrm{~Hz}, 2 \mathrm{H}, \mathrm{O}-\mathrm{CH}_{2}\right), 3.40\left(\mathrm{t}, J=5.1 \mathrm{~Hz}, 2 \mathrm{H}, \mathrm{N}_{3}-\mathrm{CH}_{2}\right), 1.57(\mathrm{dt}, J=13.2$, $\left.6.5 \mathrm{~Hz}, 4 \mathrm{H}, \mathrm{CH}_{2}\right), 1.40-1.29\left(\mathrm{~m}, J=17.9 \mathrm{~Hz}, 8 \mathrm{H}, \mathrm{CH}_{2}\right)$.

${ }^{13} \mathrm{C}-\mathrm{NMR}\left(\mathrm{CDCl}_{3}, 100 \mathrm{MHz}\right): 71.48\left(\mathrm{O}-\mathrm{CH}_{2}\right), 70.72\left(\mathrm{O}-\mathrm{CH}_{2}\right), 70.70\left(\mathrm{O}-\mathrm{CH}_{2}\right), 70.65$ $\left(\mathrm{O}-\mathrm{CH}_{2}\right), 70.61\left(\mathrm{O}-\mathrm{CH}_{2}\right), 70.08\left(\mathrm{O}-\mathrm{CH}_{2}\right), 70.04\left(\mathrm{O}-\mathrm{CH}_{2}\right), 63.01\left(\mathrm{O}-\mathrm{CH}_{2}\right), 50.70\left(\mathrm{~N}_{3}-\mathrm{CH}_{2}\right)$, 32.77 $\left(\mathrm{CH}_{2}\right), 29.60\left(\mathrm{CH}_{2}\right), 29.39\left(\mathrm{CH}_{2}\right), 29.33\left(\mathrm{CH}_{2}\right), 26.00\left(\mathrm{CH}_{2}\right), 25.66\left(\mathrm{CH}_{2}\right)$.

\subsubsection{General Procedure for the Synthesis of Azidomethacrylates 7-10}

Azido methacrylates were synthesized as published [61]. Briefly, azido linker (1 eq) and $\mathrm{NEt}_{3}(1.3 \mathrm{eq})$ were dissolved in water-free DCM in a sealed Schlenk flask under Ar atmosphere cooled in an ice bath to $0{ }^{\circ} \mathrm{C}$. Methacryloyl chloride (1.2 eq) was added dropwise to the mixture. The solution was allowed to warm to room temperature and stirred at room temperature overnight. Washing with $1 \mathrm{M} \mathrm{H}_{2} \mathrm{SO}_{4}(3 \times$, equal volume to solvent) followed by drying over $\mathrm{Na}_{2} \mathrm{SO}_{4}$ and evaporation of the solvent yielded the crude product. Further purification by column chromatography (ethyl acetate/hexane 1:10) yielded the pure products.

2-Methyl-acrylic acid 2-(2-azido-ethoxy)-ethyl ester 7

Yield: $81 \%$

${ }^{1} \mathrm{H}-\mathrm{NMR}\left(\mathrm{CDCl}_{3}, 400 \mathrm{MHz}\right): 6.17\left(\mathrm{~s}, 1 \mathrm{H}, \mathrm{CH}_{2}\right), 5.60\left(\mathrm{~s}, 1 \mathrm{H}, \mathrm{CH}_{2}\right), 4.34(\mathrm{t}, J=4.7 \mathrm{~Hz}$, $\left.2 \mathrm{H}, \mathrm{O}-\mathrm{CH}_{2}\right), 3.78\left(\mathrm{t}, J=4.7,2 \mathrm{H}, \mathrm{O}-\mathrm{CH}_{2}\right), 3.71\left(\mathrm{t}, J=5.0,2 \mathrm{H}, \mathrm{O}-\mathrm{CH}_{2}\right), 3.40(\mathrm{t}, J=4.9,2 \mathrm{H}$, $\left.\mathrm{CH}_{2}-\mathrm{N}_{3}\right), 1.98\left(\mathrm{~s}, 3 \mathrm{H}, \mathrm{CH}_{3}\right)$.

${ }^{13} \mathrm{C}-\mathrm{NMR}\left(\mathrm{CDCl}_{3}, 100 \mathrm{MHz}\right): 167.3(\mathrm{C}=\mathrm{O}), 136.1\left[\mathrm{C}\left(\mathrm{CH}_{3}\right)\left(\mathrm{CH}_{2}\right)\right], 125.9\left(\mathrm{C}=\mathrm{CH}_{2}\right)$, $70.1\left(\mathrm{O}-\mathrm{CH}_{2}\right), 69.2\left(\mathrm{O}-\mathrm{CH}_{2}\right), 63.7\left(\mathrm{O}-\mathrm{CH}_{2}\right), 50.7\left(\mathrm{~N}_{3}-\mathrm{CH}_{2}\right), 18.3\left(\mathrm{CH}_{3}\right)$.

2-Methyl-acrylic acid 2-\{2-[2-(2-azido-ethoxy)-ethoxy]-ethoxy\}-ethyl ester 8

Yield: $71 \%$

${ }^{1} \mathrm{H}-\mathrm{NMR}\left(\mathrm{CDCl}_{3}, 400 \mathrm{MHz}\right): 6.16\left(\mathrm{~s}, 1 \mathrm{H}, \mathrm{CH}_{2}\right), 5.60\left(\mathrm{~s}, 1 \mathrm{H}, \mathrm{CH}_{2}\right), 5.33(\mathrm{t}, J=4.9 \mathrm{~Hz}$, $\left.2 \mathrm{H}, \mathrm{O}-\mathrm{CH}_{2}\right), 3.77\left(\mathrm{t}, J=3.8 \mathrm{~Hz}, 2 \mathrm{H}, \mathrm{O}-\mathrm{CH}_{2}\right), 3.70\left(\mathrm{~s}, 10 \mathrm{H}, \mathrm{O}-\mathrm{CH}_{2}\right), 3,41(\mathrm{t}, J=5.0 \mathrm{~Hz}, 2 \mathrm{H}$, $\left.\mathrm{CH}_{2}-\mathrm{N}_{3}\right), 1.97\left(\mathrm{~s}, 3 \mathrm{H}, \mathrm{CH}_{3}\right)$.

${ }^{13} \mathrm{C}-\mathrm{NMR}\left(\mathrm{CDCl}_{3}, 100 \mathrm{MHz}\right): 136.2\left[\mathrm{C}\left(\mathrm{CH}_{3}\right)\left(\mathrm{CH}_{2}\right)\right], 125.8\left(\mathrm{C}=\mathrm{CH}_{2}\right), 70.8\left(\mathrm{O}-\mathrm{CH}_{2}\right)$, $70.1\left(\mathrm{O}-\mathrm{CH}_{2}\right), 69.2\left(\mathrm{O}-\mathrm{CH}_{2}\right), 63.8\left(\mathrm{O}-\mathrm{CH}_{2}\right), 50.7\left(\mathrm{~N}_{3}-\mathrm{CH}_{2}\right), 18.3\left(\mathrm{CH}_{3}\right)$.

2-Methyl-acrylic acid 2-[2-(2-\{2-[2-(2-azido-ethoxy)-ethoxy]-ethoxy\}-ethoxy)-ethoxy]-ethyl ester 9

Yield: $55 \%$

${ }^{1} \mathrm{H}-\mathrm{NMR}\left(\mathrm{CDCl}_{3}, 400 \mathrm{MHz}\right): 6.17\left(\mathrm{~s}, 1 \mathrm{H}, \mathrm{CH}_{2}\right), 5.60\left(\mathrm{~s}, 1 \mathrm{H}, \mathrm{CH}_{2}\right), 4.34(\mathrm{t}, J=4.7 \mathrm{~Hz}$, $\left.2 \mathrm{H}, \mathrm{O}-\mathrm{CH}_{2}\right), 3.78\left(\mathrm{t}, J=4.7,2 \mathrm{H}, \mathrm{O}-\mathrm{CH}_{2}\right), 3.71\left(\mathrm{t}, J=5.0,2 \mathrm{H}, \mathrm{O}-\mathrm{CH}_{2}\right), 3.40(\mathrm{t}, J=4.9,2 \mathrm{H}$, $\left.\mathrm{CH}_{2}-\mathrm{N}_{3}\right), 1.98\left(\mathrm{~s}, 3 \mathrm{H}, \mathrm{CH}_{3}\right)$.

${ }^{13} \mathrm{C}-\mathrm{NMR}\left(\mathrm{CDCl}_{3}, 100 \mathrm{MHz}\right): 167.4(\mathrm{C}=\mathrm{O}), 136.2\left[\mathrm{C}\left(\mathrm{CH}_{3}\right)\left(\mathrm{CH}_{2}\right)\right], 125.7\left(\mathrm{C}=\mathrm{CH}_{2}\right)$, $70.7\left(\mathrm{O}-\mathrm{CH}_{2}\right), 70.6\left(\mathrm{O}-\mathrm{CH}_{2}\right), 70.0\left(\mathrm{O}-\mathrm{CH}_{2}\right), 69.2\left(\mathrm{O}-\mathrm{CH}_{2}\right), 63.9\left(\mathrm{O}-\mathrm{CH}_{2}\right), 50.7\left(\mathrm{~N}_{3}-\mathrm{CH}_{2}\right)$, $18.3\left(\mathrm{CH}_{3}\right)$.

2-Methyl-acrylic acid 8-(2-\{2-[2-(2-azido-ethoxy)-ethoxy]-ethoxy\}-ethoxy)-octyl ester 10

Yield: $66 \%$

${ }^{1} \mathrm{H}-\mathrm{NMR}\left(\mathrm{CDCl}_{3}, 400 \mathrm{MHz}\right): 6.11\left(\mathrm{~s}, 1 \mathrm{H}, \mathrm{CH}_{2}\right), 5.56\left(\mathrm{~s}, 1 \mathrm{H}, \mathrm{CH}_{2}\right), 4.15(\mathrm{t}, J=6.7 \mathrm{~Hz}$, $\left.2 \mathrm{H}, \mathrm{O}-\mathrm{CH}_{2}\right), 3.72-3.64\left(\mathrm{~m}, 14 \mathrm{H}, \mathrm{O}-\mathrm{CH}_{2}\right), 3.62-3.57\left(\mathrm{~m}, 2 \mathrm{H}, \mathrm{O}-\mathrm{CH}_{2}\right), 3.46(\mathrm{t}, J=6.8 \mathrm{~Hz}, 2 \mathrm{H}$, 
$\left.\mathrm{O}-\mathrm{CH}_{2}\right), 3.41\left(\mathrm{t}, \mathrm{J}=5.1 \mathrm{~Hz}, 2 \mathrm{H}, \mathrm{N}_{3}-\mathrm{CH}_{2}\right), 1.96\left(\mathrm{~s}, 2 \mathrm{H}, \mathrm{O}-\mathrm{CH}_{2}\right), 1.73-1.64\left(\mathrm{~m}, 2 \mathrm{H}, \mathrm{O}-\mathrm{CH}_{2}\right)$, $1.62-1.57\left(\mathrm{~m}, 2 \mathrm{H}, \mathrm{O}-\mathrm{CH}_{2}\right), 1.44-1.26\left(\mathrm{~m}, 8 \mathrm{H}, \mathrm{O}-\mathrm{CH}_{2}\right)$.

${ }^{13} \mathrm{C}-\mathrm{NMR}\left(\mathrm{CDCl}_{3}, 100 \mathrm{MHz}\right): 167.56(\mathrm{C}=\mathrm{O}), 136.55\left[\mathrm{C}\left(\mathrm{CH}_{3}\right)\left(\mathrm{CH}_{2}\right)\right], 125.16\left(\mathrm{C}=\mathrm{CH}_{2}\right)$, $71.48\left(\mathrm{O}-\mathrm{CH}_{2}\right), 70.72\left(\mathrm{O}-\mathrm{CH}_{2}\right), 70.70\left(\mathrm{O}-\mathrm{CH}_{2}\right), 70.65\left(\mathrm{O}-\mathrm{CH}_{2}\right), 70.64\left(\mathrm{O}-\mathrm{CH}_{2}\right), 70.62\left(\mathrm{O}-\mathrm{CH}_{2}\right)$, $70.08\left(\mathrm{O}-\mathrm{CH}_{2}\right), 70.05\left(\mathrm{O}-\mathrm{CH}_{2}\right), 64.80\left(\mathrm{O}-\mathrm{CH}_{2}\right), 50.70\left(\mathrm{~N}_{3}-\mathrm{CH}_{2}\right), 29.61\left(\mathrm{CH}_{2}\right), 29.36\left(\mathrm{CH}_{2}\right)$, $29.21\left(\mathrm{CH}_{2}\right), 28.60\left(\mathrm{CH}_{2}\right), 26.02\left(\mathrm{CH}_{2}\right), 25.93\left(\mathrm{CH}_{2}\right), 18.34\left(\mathrm{CH}_{3}\right)$.

\subsubsection{General Procedure for Click Reaction of Azidomethacrylates with $\mathbf{1 3}$}

The click reaction was carried out under optimized conditions according to Schmidt et al. 2014 [62]. Azido methacrylate (1 eq) and propargyl GlcNAc 13 (1 eq) were dissolved in a mixture of dichloromethane/methanol/water (10:10:3). Then, $\mathrm{CuSO}_{4}(0.04 \mathrm{eq})$, tris(benzyltriazolylmethyl)amine (TBTA) (0.01 eq), and sodium ascorbate (0.22 eq) were added, and the mixture was heated to reflux for $1 \mathrm{~h}$. After cooldown and adding water, the solution was extracted 3 times with dichloromethane, the organic layer dried over $\mathrm{Na}_{2} \mathrm{SO}_{4}$, and the solvent evaporated in vacuum. Column chromatography yielded the products as yellowish oil.

2-Methyl-acrylic acid 2-\{2-[4-(3-acetylamino-4,5-dihydroxy-6-hydroxymethyl-tetrahydropyran-2-yloxymethyl)-[1,2,3] triazol-1-yl]-ethoxy\}-ethyl ester 11a

Yield: $75 \%$

${ }^{1} \mathrm{H}-\mathrm{NMR}\left(\mathrm{CDCl}_{3}, 400 \mathrm{MHz}\right): 7.67$ (s, 1H, Ar-H), 6.03 (s, 1H, CH$\left.)_{2}\right), 5.84$ (s, 1H, H-1), $5.54\left(\mathrm{~s}, 1 \mathrm{H}, \mathrm{CH}_{2}\right), 5.16(\mathrm{t}, J=9.2 \mathrm{~Hz}, 1 \mathrm{H}, \mathrm{H}-3), 5.04(\mathrm{t}, J=9.4 \mathrm{~Hz}, 1 \mathrm{H}, \mathrm{H}-4), 4.83-4.75(\mathrm{~m}, 3 \mathrm{H}$, $\left.\mathrm{O}-\mathrm{CH}_{2}+\mathrm{H}-2\right), 4.49\left(\mathrm{~s}, 2 \mathrm{H}, \mathrm{O}-\mathrm{CH}_{2}\right), 4.24-4.19\left(\mathrm{~m}, 2 \mathrm{H}, \mathrm{O}-\mathrm{CH}_{2}\right), 4.07(\mathrm{dd}, J=16.3,9.5 \mathrm{~Hz}$, 1H, H-6), 3.92 (s, 1H, H-6), $3.82\left(\mathrm{~s}, 2 \mathrm{H}, \mathrm{O}-\mathrm{CH}_{2}\right), 3.68-3.65(\mathrm{~m}, 1 \mathrm{H}, \mathrm{H}-5), 3.63$ (t, J = 4.7 Hz, $\left.2 \mathrm{H}, \mathrm{O}-\mathrm{CH}_{2}\right), 2.03\left(\mathrm{~s}, 3 \mathrm{H}, \mathrm{C}(\mathrm{O}) \mathrm{CH}_{3}\right), 1.96\left(\mathrm{~s}, 3 \mathrm{H}, \mathrm{C}(\mathrm{O}) \mathrm{CH}_{3}\right), 1.95\left(\mathrm{~s}, 3 \mathrm{H}, \mathrm{C}(\mathrm{O}) \mathrm{CH}_{3}\right), 1.87$ (s, $\left.3 \mathrm{H}, \mathrm{C}(\mathrm{O}) \mathrm{CH}_{3}\right), 1.79\left(\mathrm{~s}, 3 \mathrm{H}, \mathrm{CH}_{3}\right)$.

2-Methyl-acrylic acid 2-[2-(2-\{2-[4-(4,5-diacetoxy-6-acetoxymethyl-3-acetylaminotetrahydro-pyran-2-yloxymethyl)-[1,2,3] triazol-1-yl]-ethoxy\}-ethoxy)-ethoxy]-ethyl ester 11b

Yield: $63 \%$

${ }^{1} \mathrm{H}-\mathrm{NMR}\left(\mathrm{CDCl}_{3}, 400 \mathrm{MHz}\right): 7.58(\mathrm{~s}, 1 \mathrm{H}, \mathrm{Ar}-\mathrm{H}), 5.96\left(\mathrm{~s}, 1 \mathrm{H}, \mathrm{CH}_{2}\right), 5.71(\mathrm{~d}, J=8.5 \mathrm{~Hz}$, $1 \mathrm{H}, \mathrm{H}-1), 5.42\left(\mathrm{~s}, 1 \mathrm{H}, \mathrm{CH}_{2}\right), 5.05(\mathrm{t}, J=9.9 \mathrm{~Hz}, 1 \mathrm{H}, \mathrm{H}-3), 4.95(\mathrm{t}, J=9.6 \mathrm{~Hz}, 1 \mathrm{H}, \mathrm{H}-4), 4.78$ $(\mathrm{d}, J=12.3 \mathrm{~Hz}, 1 \mathrm{H}, \mathrm{H}-2), 4.68\left(\mathrm{dd}, J=23.6,10.5 \mathrm{~Hz}, 2 \mathrm{H}, \mathrm{O}-\mathrm{CH}_{2}-\mathrm{Ar}\right), 4.39$ (t, $J=4.7 \mathrm{~Hz}$, $\left.2 \mathrm{H}, \mathrm{O}-\mathrm{CH}_{2}\right), 4.17-4.10\left(\mathrm{~m}, 3 \mathrm{H}, \mathrm{O}-\mathrm{CH}_{2}+\mathrm{H}-6\right), 3.99(\mathrm{dd}, J=12.4,2.1 \mathrm{~Hz}, 1 \mathrm{H}, \mathrm{H}-6), 3.82$ (dd, $J=18.0,8.5 \mathrm{~Hz}, 1 \mathrm{H}, \mathrm{H}-5), 3.72\left(\mathrm{t}, J=5.0 \mathrm{~Hz}, 2 \mathrm{H}, \mathrm{O}-\mathrm{CH}_{2}\right), 3.60-3.57\left(\mathrm{~m}, 2 \mathrm{H}, \mathrm{O}-\mathrm{CH}_{2}\right)$, 3.53-3.45 (m, 10H, O- $\left.\mathrm{CH}_{2}\right), 1.94\left[\mathrm{~s}, 2 \mathrm{H}, \mathrm{C}(\mathrm{O}) \mathrm{CH}_{3}\right], 1.87\left[\mathrm{~s}, 3 \mathrm{H}, \mathrm{C}(\mathrm{O}) \mathrm{CH}_{3}\right], 1.86[\mathrm{~s}, 3 \mathrm{H}$, $\left.\mathrm{C}(\mathrm{O}) \mathrm{CH}_{3}\right], 1.79\left[\mathrm{~s}, 3 \mathrm{H}, \mathrm{C}(\mathrm{O}) \mathrm{CH}_{3}\right], 1.69\left(\mathrm{~s}, 3 \mathrm{H}, \mathrm{CH}_{3}\right)$.

2-Methyl-acrylic acid 2-(2-\{2-[2-(2-\{2-[4-(3-acetylamino-4,5-dihydroxy-6-hydroxymethyl-tetrahydro-pyran-2yloxymethyl)-[1,2,3]triazol-1-yl]-ethoxy\}-ethoxy)-ethoxy]-ethoxy\}-ethoxy)-ethyl ester 11c

Yield: $56 \%$

${ }^{1} \mathrm{H}-\mathrm{NMR}\left(\mathrm{CDCl}_{3}, 400 \mathrm{MHz}\right): 7.76(\mathrm{~s}, 1 \mathrm{H}, \mathrm{Ar}-\mathrm{H}), 6.12\left(\mathrm{~s}, 1 \mathrm{H}, \mathrm{CH}_{2}\right), 6.05$ (d, J = 8.4 Hz, $1 \mathrm{H}, \mathrm{H}-1), 5.57\left(\mathrm{~d}, J=1.6 \mathrm{~Hz}, 1 \mathrm{H}, \mathrm{CH}_{2}\right), 5.23(\mathrm{t}, J=9.9 \mathrm{~Hz}, 1 \mathrm{H}, \mathrm{H}-3), 5.09(\mathrm{t}, J=9.6 \mathrm{~Hz}, 1 \mathrm{H}$, $\mathrm{H}-4), 4.94(\mathrm{~d}, J=12.6 \mathrm{~Hz}, 1 \mathrm{H}, \mathrm{H}-2), 4.84\left(\mathrm{dd}, \mathrm{J}=33.4,10.4 \mathrm{~Hz}, 2 \mathrm{H}, \mathrm{O}-\mathrm{CH}_{2}-\mathrm{Ar}\right), 4.54(\mathrm{t}$, $\left.J=4.8 \mathrm{~Hz}, 2 \mathrm{H}, \mathrm{O}-\mathrm{CH}_{2}\right), 4.32-4.23\left(\mathrm{~m}, 3 \mathrm{H}, \mathrm{O}-\mathrm{CH}_{2}+\mathrm{H}-6\right), 4.14(\mathrm{dd}, J=12.4,2.1 \mathrm{~Hz}, 1 \mathrm{H}$, $\mathrm{H}-6), 3.87\left(\mathrm{t}, \mathrm{J}=5.0 \mathrm{~Hz}, 2 \mathrm{H}, \mathrm{O}-\mathrm{CH}_{2}\right), 3.77-3.71\left(\mathrm{~m}, 3 \mathrm{H}, \mathrm{O}-\mathrm{CH}_{2}+\mathrm{H}-5\right), 3.68-3.59$ (m, 20H, $\left.\mathrm{O}-\mathrm{CH}_{2}\right), 2.09\left(\mathrm{~s}, 3 \mathrm{H}, \mathrm{C}(\mathrm{O}) \mathrm{CH}_{3}\right), 2.02\left(\mathrm{~s}, 3 \mathrm{H}, \mathrm{C}(\mathrm{O}) \mathrm{CH}_{3}\right), 2.01\left(\mathrm{~s}, 3 \mathrm{H}, \mathrm{C}(\mathrm{O}) \mathrm{CH}_{3}\right), 1.94(\mathrm{~s}, 3 \mathrm{H}$, $\left.\mathrm{C}(\mathrm{O}) \mathrm{CH}_{3}\right), 1.85\left(\mathrm{~s}, 3 \mathrm{H}, \mathrm{CH}_{3}\right)$. 
2-Methyl-acrylic acid

8-\{2-[2-(2-\{2-[4-(4,5-diacetoxy-6-acetoxymethyl-3-acetylamino-tetrahydro-pyran-2-

yloxymethyl)-[1,2,3]triazol-1-yl]-ethoxy\}-ethoxy)-ethoxy]-ethoxy\}-octyl ester 11d

Yield: $86 \%$

${ }^{1} \mathrm{H}-\mathrm{NMR}\left(\mathrm{CDCl}_{3}, 400 \mathrm{MHz}\right): 7.61(\mathrm{~s}, 1 \mathrm{H}, \mathrm{Ar}-\mathrm{H}), 5.94\left(\mathrm{~s}, 1 \mathrm{H}, \mathrm{CH}_{2}\right), 5.85(\mathrm{~d}, J=8.6 \mathrm{~Hz}$, $1 \mathrm{H}, \mathrm{H} 1), 5.39\left(\mathrm{~s}, 1 \mathrm{H}, \mathrm{CH}_{2}\right), 5.08(\mathrm{t}, J=9.9 \mathrm{~Hz}, 1 \mathrm{H}, \mathrm{H} 3), 4.94(\mathrm{t}, J=9.6 \mathrm{~Hz}, 1 \mathrm{H}, \mathrm{H} 4), 4.82-4.60$ $\left(\mathrm{m}, 3 \mathrm{H}, \mathrm{H} 2+\mathrm{Ar}-\mathrm{CH}_{2}-\mathrm{O}\right), 4.41-4.34\left(\mathrm{~m}, 2 \mathrm{H}, \mathrm{O}-\mathrm{CH}_{2}\right), 4.25-4.08(\mathrm{~m}, 2 \mathrm{H}, \mathrm{H} 6), 4.02-3.92(\mathrm{~m}$, $\left.2 \mathrm{H}, \mathrm{O}-\mathrm{CH}_{2}\right), 3.63-3.54(\mathrm{~m}, 1 \mathrm{H}, \mathrm{H} 5), 3.51-3.45\left(\mathrm{~m}, 10 \mathrm{H}, \mathrm{O}-\mathrm{CH}_{2}\right), 3.43-3.39\left(\mathrm{~m}, 2 \mathrm{H}, \mathrm{O}-\mathrm{CH}_{2}\right)$, $3.28\left(\mathrm{t}, J=6.8 \mathrm{~Hz}, 2 \mathrm{H}, \mathrm{O}-\mathrm{CH}_{2}\right), 1.94\left(\mathrm{~s}, 3 \mathrm{H}, \mathrm{CH}_{3}\right), 1.87\left(\mathrm{~s}, 3 \mathrm{H}, \mathrm{CH}_{3}\right), 1.86\left(\mathrm{~s}, 3 \mathrm{H}, \mathrm{CH}_{3}\right), 1.78$ $\left(\mathrm{s}, 3 \mathrm{H}, \mathrm{CH}_{3}\right), 1.69\left(\mathrm{~s}, 3 \mathrm{H}, \mathrm{CH}_{3}\right), 1.56-1.37\left(\mathrm{~m}, 5 \mathrm{H}, \mathrm{CH}_{2}\right), 1.22-1.13\left(\mathrm{~m}, 9 \mathrm{H}, \mathrm{CH}_{2}\right)$.

2.1.7. General Procedure for Click Reaction of Azidomethacrylates with Propargyl Alcohol

The click reaction with propargyl alcohol was carried out under conditions as previously published [62]. Briefly, azido methacrylate (1 eq) and propargyl alcohol (1.3 eq) were dissolved in a mixture of dichloromethane/methanol/water (10:10:3). Then, $\mathrm{CuSO}_{4}$ $(0.04 \mathrm{eq})$, TBTA $(0.01 \mathrm{eq})$, and sodium ascorbate $(0.22 \mathrm{eq})$ were added, and the mixture was heated to reflux overnight. After cooldown and adding water, the solution was extracted 3 times with dichloromethane, the organic layer dried over $\mathrm{Na}_{2} \mathrm{SO}_{4}$, and the solvent evaporated in vacuo. Column chromatography (ethyl acetate/methanol, 4:1) yielded the products as yellow oils.

2-Methyl-acrylic acid 2-[2-(4-hydroxymethyl-[1,2,3]triazol-1-yl)-ethoxy]-ethyl ester 12a

Yield: $18 \%$

${ }^{1} \mathrm{H}-\mathrm{NMR}\left(\mathrm{CDCl}_{3}, 200 \mathrm{MHz}\right): 7.68(\mathrm{~s}, 1 \mathrm{H}, \mathrm{Ar}-\mathrm{H}), 6.10\left(\mathrm{dd}, J=1.5,1.0 \mathrm{~Hz}, 1 \mathrm{H}, \mathrm{CH}_{2}\right)$, $5.60\left(\mathrm{p}, J=1.6 \mathrm{~Hz}, 1 \mathrm{H}, \mathrm{CH}_{2}\right), 4.77\left(\mathrm{~s}, 2 \mathrm{H}, \mathrm{CH}_{2}\right), 4.54\left(\mathrm{t}, J=5.0 \mathrm{~Hz}, 2 \mathrm{H}, \mathrm{O}-\mathrm{CH}_{2}\right), 4.29(\mathrm{t}$, $\left.J=4.7 \mathrm{~Hz}, 2 \mathrm{H}, \mathrm{O}-\mathrm{CH}_{2}\right), 3.87\left(\mathrm{t}, J=5.1 \mathrm{~Hz}, 2 \mathrm{H}, \mathrm{O}-\mathrm{CH}_{2}\right), 3.69(\mathrm{ddd}, J=5.4,4.0,2.1 \mathrm{~Hz}, 2 \mathrm{H}$, $\left.\mathrm{O}-\mathrm{CH}_{2}\right), 1.94\left(\mathrm{dd}, \mathrm{J}=1.5,1.0 \mathrm{~Hz}, 3 \mathrm{H}, \mathrm{CH}_{3}\right)$.

${ }^{13} \mathrm{C}-\mathrm{NMR}\left(\mathrm{CDCl}_{3}, 50 \mathrm{MHz}\right): 125.88\left(\mathrm{C}=\mathrm{CH}_{2}\right), 115.58,69.40\left(\mathrm{O}-\mathrm{CH}_{2}\right), 69.20\left(\mathrm{O}-\mathrm{CH}_{2}\right)$, $69.04\left(\mathrm{O}-\mathrm{CH}_{2}\right), 63.42\left(\mathrm{O}-\mathrm{CH}_{2}\right), 50.30\left(\mathrm{~N}-\mathrm{CH}_{2}\right), 18.21\left(\mathrm{CH}_{3}\right)$.

2-Methyl-acrylic acid 2-[2-(4-hydroxymethyl-[1,2,3]triazol-1-yl)-ethoxy]-ethyl ester 12b

Yield: 39\%

${ }^{1} \mathrm{H}-\mathrm{NMR}\left(\mathrm{CDCl}_{3}, 200 \mathrm{MHz}\right): 7.76(\mathrm{~s}, 1 \mathrm{H}, \mathrm{Ar}-\mathrm{H}), 6.11\left(\mathrm{dd}, J=1.5,0.9 \mathrm{~Hz}, 1 \mathrm{H}, \mathrm{CH}_{2}\right)$, $5.57\left(\mathrm{p}, J=1.6 \mathrm{~Hz}, 1 \mathrm{H}, \mathrm{CH}_{2}\right), 4.78\left(\mathrm{~s}, 2 \mathrm{H}, \mathrm{CH}_{2}\right), 4.53\left(\mathrm{t}, J=5.3 \mathrm{~Hz}, 2 \mathrm{H}, \mathrm{CH}_{2}\right), 4.29(\mathrm{dd}, J=5.7$, $\left.4.2 \mathrm{~Hz}, 2 \mathrm{H}, \mathrm{CH}_{2}\right), 3.86\left(\mathrm{t}, J=5.2 \mathrm{~Hz}, 2 \mathrm{H}, \mathrm{CH}_{2}\right), 3.74\left(\mathrm{dd}, J=5.5,4.2 \mathrm{~Hz}, 2 \mathrm{H}, \mathrm{CH}_{2}\right), 3.67-3.57$ $\left(\mathrm{m}, 8 \mathrm{H}, \mathrm{CH}_{2}\right), 1.93\left(\mathrm{~s}, 3 \mathrm{H}, \mathrm{CH}_{3}\right)$.

${ }^{13} \mathrm{C}-\mathrm{NMR}\left(\mathrm{CDCl}_{3}, 50 \mathrm{MHz}\right): 125.68\left[\mathrm{C}\left(\mathrm{CH}_{3}\right)\left(\mathrm{CH}_{2}\right)\right], 122.87\left(\mathrm{C}=\mathrm{CH}_{2}\right), 70.62\left(\mathrm{O}-\mathrm{CH}_{2}\right)$, $70.58\left(\mathrm{O}-\mathrm{CH}_{2}\right), 70.51\left(\mathrm{O}-\mathrm{CH}_{2}\right), 70.48\left(\mathrm{O}-\mathrm{CH}_{2}\right), 69.41\left(\mathrm{O}-\mathrm{CH}_{2}\right), 69.12\left(\mathrm{O}-\mathrm{CH}_{2}\right), 63.74$ $\left(\mathrm{O}-\mathrm{CH}_{2}\right), 56.52\left(\mathrm{O}-\mathrm{CH}_{2}\right), 50.23\left(\mathrm{~N}-\mathrm{CH}_{2}\right), 18.21\left(\mathrm{CH}_{3}\right)$.

2-Methyl-acrylic acid 2-\{2-[2-(2-\{2-[2-(4-hydroxymethyl-[1,2,3]triazol-1-yl)-ethoxy]-ethoxy\}ethoxy)-ethoxy]-ethoxy\}-ethyl ester 12c

Yield: $96 \%$

${ }^{1} \mathrm{H}-\mathrm{NMR}\left(\mathrm{CDCl}_{3}, 600 \mathrm{MHz}\right): 7.86(\mathrm{~s}, 1 \mathrm{H}, \mathrm{Ar}-\mathrm{H}), 6.12\left(\mathrm{dd}, J=1.6,1.0 \mathrm{~Hz}, 2 \mathrm{H}, \mathrm{CH}_{2}\right)$, $5.56\left(\mathrm{q}, J=1.6 \mathrm{~Hz}, 2 \mathrm{H}, \mathrm{CH}_{2}\right), 4.79\left(\mathrm{~s}, 2 \mathrm{H}, \mathrm{CH}_{2}\right), 4.54\left(\mathrm{t}, J=4.9 \mathrm{~Hz}, 2 \mathrm{H}, \mathrm{CH}_{2}\right), 4.30-4.27(\mathrm{~m}$, $\left.2 \mathrm{H}, \mathrm{CH}_{2}\right), 3.86\left(\mathrm{t}, J=4.9 \mathrm{~Hz}, 2 \mathrm{H}, \mathrm{CH}_{2}\right), 3.72\left(\mathrm{dd}, J=5.5,4.3 \mathrm{~Hz}, 2 \mathrm{H}, \mathrm{CH}_{2}\right), 3.65-3.59(\mathrm{~m}$, $\left.16 \mathrm{H}, \mathrm{CH}_{2}\right), 2.37(\mathrm{~s}, 1 \mathrm{H}, \mathrm{OH}), 1.94\left(\mathrm{dd}, J=1.5,1.0 \mathrm{~Hz}, 3 \mathrm{H}, \mathrm{CH}_{3}\right)$.

${ }^{13} \mathrm{C}-\mathrm{NMR}\left(\mathrm{CDCl}_{3}, 200 \mathrm{MHz}\right): 136.12\left[\mathrm{C}\left(\mathrm{CH}_{3}\right)\left(\mathrm{CH}_{2}\right)\right], 125.72\left(\mathrm{C}=\mathrm{CH}_{2}\right), 70.60\left(\mathrm{O}-\mathrm{CH}_{2}\right)$, $70.57\left(\mathrm{O}-\mathrm{CH}_{2}\right), 70.56\left(\mathrm{O}-\mathrm{CH}_{2}\right), 70.54\left(\mathrm{O}-\mathrm{CH}_{2}\right), 70.53\left(\mathrm{O}-\mathrm{CH}_{2}\right), 70.48\left(\mathrm{O}-\mathrm{CH}_{2}\right), 70.46$ $\left(\mathrm{O}-\mathrm{CH}_{2}\right), 70.38\left(\mathrm{O}-\mathrm{CH}_{2}\right), 69.38\left(\mathrm{O}-\mathrm{CH}_{2}\right), 69.10\left(\mathrm{O}-\mathrm{CH}_{2}\right), 64.34\left(\mathrm{O}-\mathrm{CH}_{2}\right), 63.81\left(\mathrm{O}-\mathrm{CH}_{2}\right)$, $57.20\left(\mathrm{O}-\mathrm{CH}_{2}\right), 56.62\left(\mathrm{O}-\mathrm{CH}_{2}\right), 50.34\left(\mathrm{~N}_{3}-\mathrm{CH}_{2}\right), 30.57\left(\mathrm{CH}_{2}\right), 18.28\left(\mathrm{CH}_{3}\right)$. 


\subsubsection{General Procedure for Free Radical Polymerization}

Combined monomers (in general, dimethacrylamide, benzophenone methacrylate 14 and functional methacrylate 11a-d or 12a-c in given ratios (Table 1) were dissolved in water-free THF under Ar atmosphere to a total monomer concentration of $2 \mathrm{M}$. Azobisisobutyronitrile (AIBN) $(0.01 \mathrm{~mol} \%)$ was added and the reaction mixture heated to reflux for $16 \mathrm{~h}$. Cooldown followed by precipitation of the polymers in 10-fold excess iso-hexane yielded the product as a white precipitate. The precipitate was dissolved in water and lyophilized to obtain the product as a white powder.

Table 1. Overview of the synthesized PDMAm-polymers.

\begin{tabular}{|c|c|c|c|}
\hline \multirow{2}{*}{ Polymer } & \multicolumn{2}{|c|}{ Calculated Ratio } & \multirow{2}{*}{$\begin{array}{c}\text { Found Ratio (via NMR) } \\
\text { MBP vs. 11/12 }\end{array}$} \\
\hline & MBP $14[\%]^{(a)}$ & 11 or $12[\%]^{(b)}$ & \\
\hline GlcNAc-2EG & $5 \%$ & $5 \% 11 a$ & $30: 1$ \\
\hline 5\%-GlcNAc-4EG & $5 \%$ & $5 \% 11 b$ & $2: 1$ \\
\hline $10 \%$-GlcNAc- 4 EG & $5 \%$ & $10 \% 11 b$ & $1: 2$ \\
\hline 25\%-GlcNAc-4EG & $5 \%$ & $25 \% 11 b$ & $1: 5$ \\
\hline $50 \%-G l c N A c-4 E G$ (c) & $5 \%$ & $50 \% 11 b$ & - \\
\hline GlcNAc-6EG & $5 \%$ & $5 \% 11 c$ & $3: 1$ \\
\hline GlcNAc-4EG-octyl & $5 \%$ & $5 \% 11 d$ & $6: 1$ \\
\hline HM-2EG & $5 \%$ & $5 \% 12 a$ & $1: 1$ \\
\hline HM-4EG & $5 \%$ & $5 \% 12 b$ & $1: 1$ \\
\hline HM-6EG & $5 \%$ & $5 \% 12 c$ & $1: 1$ \\
\hline PDMAm $^{(\mathrm{d})}$ & $5 \%$ & - & - \\
\hline
\end{tabular}

(a) 4-methacryloyloxy-benzophenone (MBP). ${ }^{\text {(b) }}$ Functional GlcNAc monomers (11), Functional 4-hydroxymethyl monomers (12). (c) The 50\%-GlcNAc-4EG polymer could not be obtained; instead, the reaction resulted in ester hydrolysis of the methacrylic acid ester, yielding the GlcNAc-tetraethylene glycol clickamer only. ${ }^{(d)}$ The PDMAm polymer is the dimethacrylamide-co-methacryloyl benzophenone copolymer without additional functionality, serving as control for cell culture and microbiology experiments.

\subsubsection{General Deprotection Procedure of GlcNAc Polymers}

Deprotection was carried out according to a standard Zemplén procedure [63]. GlcNAc polymers were dissolved in dry methanol in a sealed tube under Ar atmosphere. $\mathrm{NaOMe}$ ( $30 \%$ solution in methanol; 0.2 eq referring to glycoside content) was added and the mixture stirred at room temperature overnight. Water was added until the precipitated polymers were dissolved. Addition of ion exchange resin (Dowex 50WX8, 200-400 mesh, Carl Roth, Karlsruhe, Germany) followed by filtration and lyophilization yielded the products as yellowish powders. The crude polymer was further purified by 3 times dissolving in methanol and precipitation in 10-fold excess of $\mathrm{Et}_{2} \mathrm{O}$, followed by dissolution in $\mathrm{ddH}_{2} \mathrm{O}$ and lyophilization. Pure polymers were obtained as white powder.

\subsection{Preparation of Polymer Coatings}

Polymers were diluted to a concentration of 25 or $5 \mathrm{mg} / \mathrm{mL}$ in a $\mathrm{H}_{2} \mathrm{O} /$ ethanol 5:1 mixture. The mixture was sterile filtered before use. From the mixture, $20 \mu \mathrm{L}$ was pipetted into each well of a 48 -well plate, $34.6 \mu \mathrm{L}$ into each well of a 24 -well plate, or $5.76 \mu \mathrm{L}$ into each well of a 96-well plate. The plates were allowed to dry under sterile conditions for at least $4 \mathrm{~h}$ and crosslinked with $3 \mathrm{~J} / \mathrm{cm}^{2} \mathrm{UV}$ light at $254 \mathrm{~nm}$, followed by $3 \times$ washings with $250 \mu \mathrm{L}$ of phosphate-buffered saline (PBS).

Coverslips were coated by carefully pipetting $10 \mu \mathrm{L}$ of each polymer solution on a 13-mm PETG coverslip (Tissue Culture Coverslips 13 mm, Sarstedt, Nümbrecht, Germany) to obtain a fully coated surface. The coverslips were let dry in air for at least $4 \mathrm{~h}$, followed by crosslinking with $3 \mathrm{~J} / \mathrm{cm}^{2}$ at $254 \mathrm{~nm}$. Washing $3 \times$ with $\mathrm{ddH}_{2} \mathrm{O}$ and $3 \times$ with ethanol, followed by drying in an $\mathrm{N}_{2}$ stream yielded the final coating, which was used directly for IR spectroscopy. 


\subsection{Physicochemical Surface Characterization}

IR data was recorded on a Tensor 27 FT-IR Spectrometer (Bruker, Germany). Scanning electron microscope (SEM) images were obtained with an XL-30 SEM (Philips, Amsterdam, Netherlands) at $10 \mathrm{kV}$. The samples were dried in vacuum and thereafter coated with an approx. $5 \mathrm{~nm}$ thick $\mathrm{Au} / \mathrm{Pd}$ layer (SC7620 sputter coater, Quorum, Laughton, UK). Images were taken at a $40^{\circ}$ tilted angle. Atomic force microscope (AFM) images were obtained using a CoreAFM (Nanosurf, Liestal, Switzerland) with a TAP150GD-G tip (BudgetSensors, Sofia, Bulgaria, tip radius $<10 \mathrm{~nm}$ ) in tapping mode.

\subsection{Biological Evaluation}

\subsubsection{L-929 Mouse Fibroblast Cell Culture}

L-929 mouse fibroblasts were a gift from Dr. Oliver Podlech (CleanControlling $\mathrm{GmbH}$, Emmingen-Liptingen, Germany). Media and reagents were purchased from Sigma-Aldrich (Taufkirchen, Germany). Sterile cell cultureware was purchased from VWR, Germany. Fibroblasts were cultured in low-glucose Dulbecco's Modified Eagle Medium (DMEM), supplemented with $10 \%(v / v)$ fetal calf serum $(\mathrm{FCS}), 1 \%(v / v)$ penicillin-streptomycin $(10,000 \mathrm{U} / \mathrm{mL})$ and $1 \%(v / v)$ L-glutamine. Cells were incubated at $37{ }^{\circ} \mathrm{C}$ and $5 \% \mathrm{CO}_{2}$ in a humidified incubator (CB series C150, Binder, Tuttlingen, Germany) and subculturing was performed using trypsin/Ethylenediaminetetraacetic acid (EDTA) before reaching confluency, approximately every third day.

\subsubsection{Extract Test Using the MTT Assay}

Polymer extracts were prepared according to USP standard [64]. Briefly, after coating a 24-well plate with polymers followed by washing steps, $317 \mu \mathrm{L}$ of DMEM ( $20 \mathrm{~mL}$ for $120-\mathrm{cm}^{2}$ coated surface) was added and the coating incubated for $24 \mathrm{~h}$ at $37{ }^{\circ} \mathrm{C}$ in a humidified $5 \% \mathrm{CO}_{2}$ atmosphere. A cell suspension of L-929 in DMEM $(100,000$ cells $/ \mathrm{mL})$ was added to an uncoated 96-well plate (treated for cell culture, $100 \mu \mathrm{L} /$ well) and grown to adherence overnight. Medium in each well was replaced by prepared extract medium $(100 \mu \mathrm{L})$ or medium containing $6 \%$ Dimethyl sulfoxide (DMSO) for the cytotoxicity positive control and incubated for $72 \mathrm{~h}$ at $37^{\circ} \mathrm{C}$ in a humidified $5 \% \mathrm{CO}_{2}$ atmosphere. After $72 \mathrm{~h}$, medium was replaced by $110 \mu \mathrm{L}$ of DMEM containing $10 \%$ of a $10 \mathrm{mM}$ MTT solution in PBS. After incubating for $4 \mathrm{~h}$ in the incubator, $100 \mu \mathrm{L}$ of $10 \%$ SDS in $0.01 \mathrm{M} \mathrm{HCl}$ solution was added and incubated for $4 \mathrm{~h}$. Absorbance was measured at $570 \mathrm{~nm}$ using a Tecan Infinite M2000 microplate reader. Cell viability was calculated as the percentage ratio of averaged absorbance of triplicate wells containing extract versus the averaged absorbance of untreated control wells.

\subsubsection{Direct Contact Test Using the MTT Assay}

Cell suspension $(100,000$ cells $/ \mathrm{mL})$ was added to a polymer-coated $96-$ well plate (treated for cell culture, $100 \mu \mathrm{L}$ each) and incubated over 24 and $48 \mathrm{~h}$ at $37^{\circ} \mathrm{C}$ and $5 \% \mathrm{CO}_{2}$ in a humidified incubator. At the end of incubation, the medium was removed, and $110 \mu \mathrm{L}$ of medium containing $10 \%$ of a $10 \mathrm{mM}$ MTT solution in PBS was added. After incubating the cells for $4 \mathrm{~h}$ at $37^{\circ} \mathrm{C}$ in a humidified $5 \% \mathrm{CO}_{2}$ atmosphere, $100 \mu \mathrm{L}$ of $10 \%$ SDS in $0.01 \mathrm{M}$ $\mathrm{HCl}$ was added and incubated for $4 \mathrm{~h}$ at $37^{\circ} \mathrm{C}$ in $5 \% \mathrm{CO}_{2}$. The absorbance was measured at $570 \mathrm{~nm}$ using a microplate reader. Cell viability was calculated as the percentage ratio of averaged absorbance of each triplicate well containing the same polymer coating versus the averaged absorbance of uncoated control wells.

\subsubsection{Bacterial Cell Culture}

For antimicrobial tests, bacteria cell lines of Staphylococcus aureus (MRSA, DSM 28766) and Escherichia coli (K12, DSM 498) were used. Bacterial strains were stored at $-80{ }^{\circ} \mathrm{C}$ in glycerol stocks. For each experiment, a new vial of bacterial strain was thawed and incubated (Minitron, Infors HT, Bottmingen, Switzerland) overnight at $37^{\circ} \mathrm{C}$ and $100 \mathrm{rpm}$ in LB medium before use in the experiments. 


\subsubsection{Antibacterial Assay by Optical Density}

The antibacterial effects of the polymers were evaluated using a direct contact method according to ISO 22196 [65] with a thin film of bacteria solution in LB medium (highnutrition) or PBS (low-nutrition) between the polymer to be analyzed and a polymer slide to ensure direct contact. A 24-well cell culture tissue plate coated with the polymers to be tested was inoculated with $100 \mu \mathrm{L}$ of bacterial suspension at a concentration of $3 \times 10^{5}$ cells $/ \mathrm{mL}$ and sealed with a PETG coverslip. Bacterial solutions were prepared in LB medium for the high-nutrition condition and in PBS for the low-nutrition condition. As controls, wells without polymer coating were treated with bacteria suspension and medium without cells. After incubating the plate for $24 \mathrm{~h}$ at $37^{\circ} \mathrm{C}$ and $90 \%$ humidity, bacteria were removed from the plates by addition of $1 \mathrm{~mL}$ of soybean casein digest lecithin polysorbate broth (SCDLP), followed by pipetting up and down 4 times to detach all bacteria. From this mixture, $200 \mu \mathrm{L}$ was transferred to a 96-well plate in a series of dilutions. The 96-well plate was sealed with parafilm and placed in a plate reader preheated to $37^{\circ} \mathrm{C}$. Optical density at $600 \mathrm{~nm}$ was measured every $30 \mathrm{~min}$ over the next $12 \mathrm{~h}$. The plate was shaken briefly every $10 \mathrm{~min}$ to ensure distribution of nutrients. Measured values from each sample were compared to determine the viability relative to that of untreated samples. The evaluation time point was chosen to be in the exponential phase before reaching the inflection point. For evaluation, the last time point was used for which Equation (1) was still fulfilled:

$$
\frac{\log \left(\mathrm{OD}_{600 \mathrm{~nm}, \mathrm{t}_{+1}}\right)-2 \times \log \left(\mathrm{OD}_{600 \mathrm{~nm}, \mathrm{t}}\right)+\log \left(\mathrm{OD}_{600 \mathrm{~nm}, \mathrm{t}_{-1}}\right)}{\mathrm{t}-\mathrm{t}_{-1}}>0
$$

where $\mathrm{OD}_{600 \mathrm{~nm}}$ is the optical density at $600 \mathrm{~nm}$ for the different measuring points; $\mathrm{t}$ is the measuring time of the data point to be evaluated; $t_{+1}$ is the measuring point of the subsequent data point and $t_{-1}$ is the measuring point of the previous data point.

\subsubsection{Antibacterial Assay by Colony-Forming Units}

The antibacterial effects of the polymers were evaluated using a direct contact method as a droplet of bacteria solution in PBS on top of the polymer. A bacterial overnight culture in LB medium was centrifuged (10 min, $4000 \times g)$ and resuspended in PBS to an $\mathrm{OD}_{600}$ value of 0.2. Coated and uncoated PETG coverslips were inoculated in a 6-well tissue culture plate with $100 \mu \mathrm{L}$ of the prepared bacteria suspension. Uncoated PETG coverslips were used as reference. The samples were cultured for $24 \mathrm{~h}$ at $37^{\circ} \mathrm{C}$ and $90 \%$ humidity in a humid chamber. Solutions were removed and transferred to a sterile tube. Each coverslip was transferred to a $15 \mathrm{~mL}$ Falcon tube, covered with $900 \mu \mathrm{L}$ of PBS, and treated in an ultrasonic bath at $50 \mathrm{~Hz}$ for $15 \mathrm{~min}$ to remove bacteria. Both PBS fractions were combined, vortexed for $1 \mathrm{~min}$, and pipetted in a series of dilutions on LB agar plates in duplicate (100 $\mu \mathrm{L}$ per dilution and plate). Agar plates were cultured at $37^{\circ} \mathrm{C}$ in an incubator, followed by counting of colony-forming units (CFU) after $24 \mathrm{~h}$.

\subsubsection{Crystal Violet Assay for Biofilm Assessment}

Biofilm formation was assessed in 96-well plates by staining with crystal violet dye. Briefly, $200 \mu \mathrm{L}$ of a bacterial overnight culture, adjusted to a concentration of $3 \times 10^{5}$ cells $/ \mathrm{mL}$ in lysogeny broth (LB) medium, was added to each sample. Empty wells (in the outer row, in particular) were filled with $200 \mu \mathrm{L}$ of PBS to prevent the samples from drying out. The closed well plate was incubated for 24,48 , or $72 \mathrm{~h}$ at $37^{\circ} \mathrm{C}$ in an incubator without shaking. Then, $\mathrm{OD}_{600}$ was measured to ensure comparable cell growth in each well. The medium was gently discarded without removing the biofilm, and the samples were washed carefully 3 times with PBS, followed by fixing with $200 \mu \mathrm{L}$ of absolute ethanol. The ethanol was aspirated, and the samples were dried for $10 \mathrm{~min}$ under sterile conditions. For biofilm staining, $200 \mu \mathrm{L}$ of $0.5 \mathrm{wt} \%(w t / v o l)$ crystal violet staining solution in PBS was added to each sample, and the plate was incubated for $2 \mathrm{~min}$ at room temperature. The staining solution was removed and the samples washed $6 \times$ with $200 \mu \mathrm{L}$ 
of PBS to remove excess dye. The samples were left to dry overnight under a sterile bench, followed by addition of $100 \mu \mathrm{L}$ of ethanol to release the dye. After a 10 min incubation, the mixture in each well was transferred to a new 96-well plate, and absorbance at $595 \mathrm{~nm}$ was measured using a plate reader.

\subsubsection{Extracellular Polymeric Substance (EPS) Assessment by Phenol-Sulfuric} Acid Method

In addition, the biofilm formation was assessed by analyzing the carbohydrates in the formed biofilm. Therefore, the phenol-sulfuric acid method according to Masuko et al. [66] was performed. Briefly, polymer coatings were treated in a 96-well plate as previously described for the crystal violet assay and incubated for 24,48 and $72 \mathrm{~h}$ at $37{ }^{\circ} \mathrm{C}$ in an incubator without shaking. $\mathrm{OD}_{600}$ was measured to ensure comparable cell growth in each well, and the medium was gently discarded. After 3 wash steps with sterile PBS, the samples were fixed with $200 \mu \mathrm{l}$ of absolute ethanol. The ethanol was gently aspirated, and the samples were dried for 10 min under sterile conditions. A volume of $150 \mu l$ of concentrated sulfuric acid was added to each well, immediately followed by $30 \mu \mathrm{l}$ of $5 \%$ phenol in water. The plate was incubated at $90{ }^{\circ} \mathrm{C}$ for $5 \mathrm{~min}$ and then cooled in an ice bath for an additional $5 \mathrm{~min}$. The absorbance at $490 \mathrm{~nm}$ was measured using a plate reader to quantify EPS.

\subsubsection{Live/Dead Staining}

Besides the Crystal violet staining and EPS assessment, we also performed live/dead staining using the bacteria live/dead staining kit (PromoCell GmbH, Heidelberg, Germany). Polymer coatings were treated in a 96-well plate as previously described for the crystal violet assay and incubated for 24,48 and $72 \mathrm{~h}$ at $37{ }^{\circ} \mathrm{C}$ in an incubator without shaking and stained accordingly to the manufacturer's instructions. Briefly, biofilm samples were washed 3 times with sterile $150 \mathrm{mM} \mathrm{NaCl}$ solution and stained for $15 \mathrm{~min}$ at room temperature in the dark with an appropriate mixture of DMAO (ex/em 490/540) and EthDIII (ex/em 530/630). Live bacteria with an intact cell membrane are stained fluorescent green, whereas dead bacteria with a disrupted cell membrane are stained fluorescent red. Labeled cells were imaged using the fluorescent microscope Observer.Z1 (Carl Zeiss AG, Oberkochen, Germany) and processed using the software ZEN blue edition (Version 3.4, Carl Zeiss AG, Oberkochen, Germany).

\subsubsection{Statistical Analysis}

Measurements for biological evaluation (bacterial and cell culture) were replicated with $n=3$ and expressed as mean \pm standard deviation (SD) unless stated otherwise. Statistical significance was analyzed with pairwise Student's $t$-test, and statistically significant values were defined as $p<0.05\left(^{*}\right)$.

\section{Results and Discussion}

\subsection{Monomer Synthesis}

Azido linkers 3-6 were synthesized by sequential tosylation steps, followed by substitution with either sodium azide or another linker fragment. Those prolonged linkers were reacted to azido methacrylate 7-10, followed by click reaction to either functional GlcNAc methacrylate 11a-d or their corresponding 4-hydroxymethyl methacrylate derivatives 12a-c. The detailed reaction sequences are shown in Figure 1. 
A) Reaction sequences leading to functional monomers:

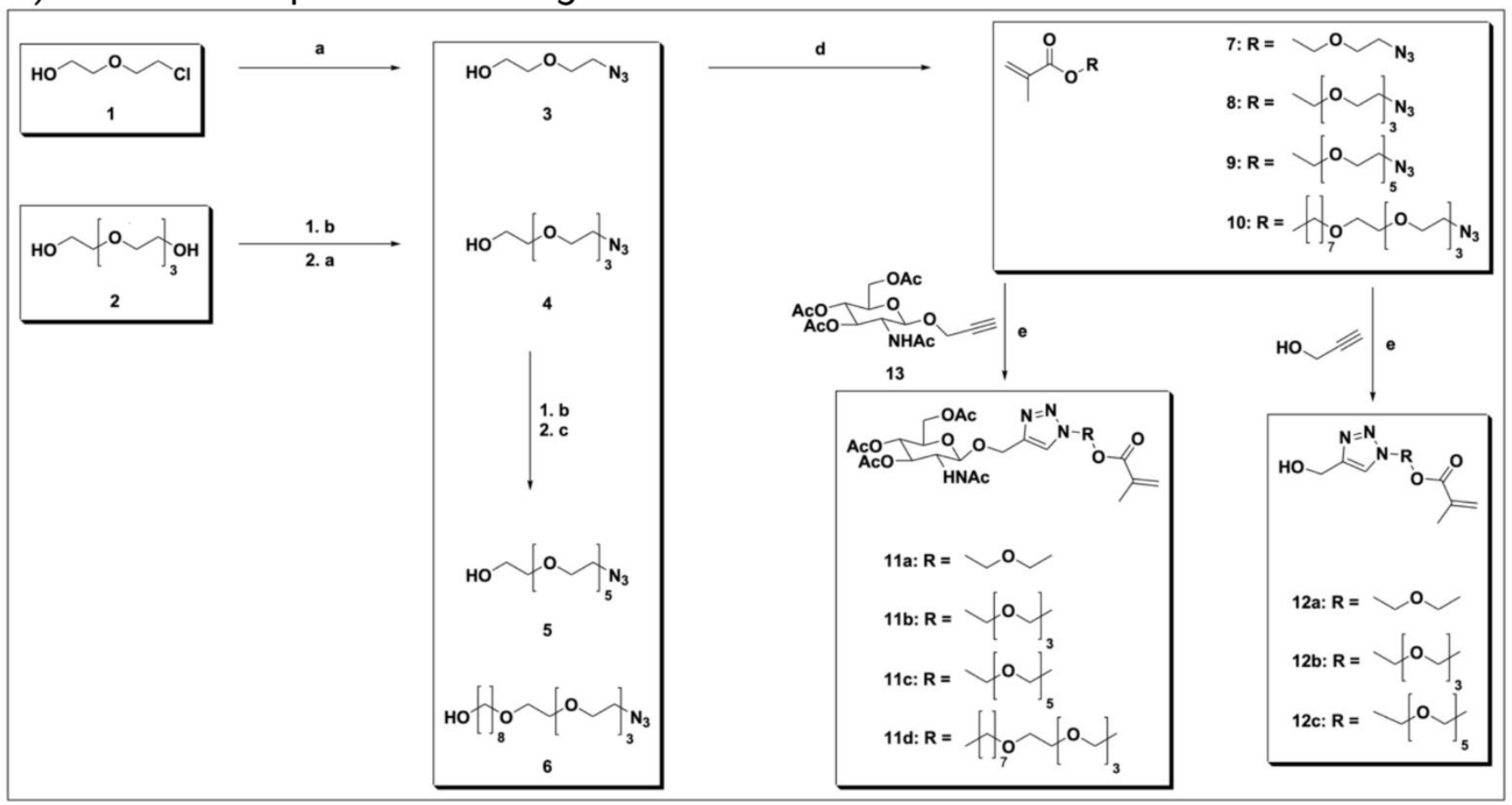

B) Polymer synthesis of functional GlcNAc-containing polymers:

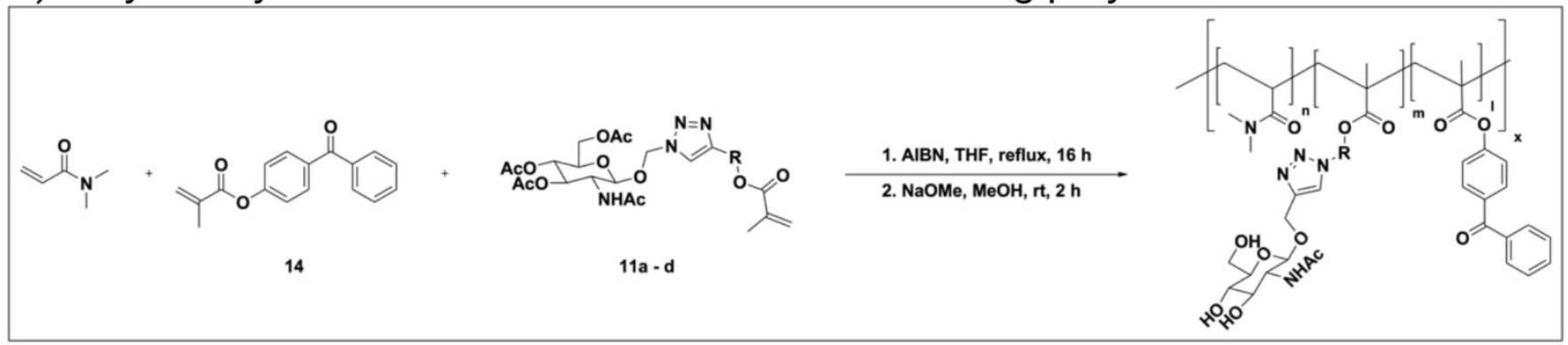

C) Polymer synthesis of functional 4-hydroxymethyl derivatives:

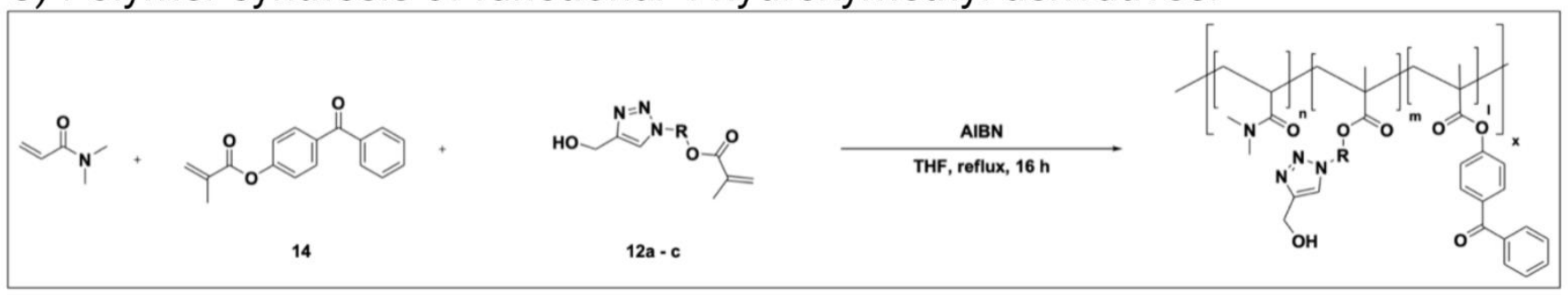

Figure 1. Chemical Synthesis. (A) Reaction sequences leading to functional monomers 11a-d or 12a-c, respectively. Reaction conditions: (a) $\mathrm{NaN}_{3}, \mathrm{CH}_{3} \mathrm{CN}$, reflux, 16 h; (b) TsCl, $\mathrm{NEt}_{3}, \mathrm{CH}_{2} \mathrm{Cl}_{2}, \mathrm{rt}, 16$ h; (c) NaH, THF, reflux, 48 h; (d) methacryloyl chloride, $\mathrm{NEt}_{3}, \mathrm{CH}_{2} \mathrm{Cl}_{2}, 0{ }^{\circ} \mathrm{C}-\mathrm{rt}, 16 \mathrm{~h}$; and (e) $\mathrm{CuSO}_{4}, \mathrm{TBTA}, \mathrm{Na}$ ascorbate, $\mathrm{H}_{2} \mathrm{O} / \mathrm{MeOH} / \mathrm{CH}_{2} \mathrm{Cl}_{2}$ 3:10:10, $60{ }^{\circ} \mathrm{C}, 1 \mathrm{~h}$. (B) Polymer synthesis of functional $\mathrm{N}$-acetylglucosamine (GlcNAc)-containing polymers. Benzophenone methacrylate $\mathbf{1 4}$ was copolymerized with glycosidic monomers 11a-d by free radical polymerization with AIBN, followed by Zemplén deprotection. (C) Polymer synthesis of functional 4-hydroxymethyl derivatives using 4-hydroxymethyl-[1,2,3]-triazo-1-yl derivatives of functional monomers 12a-c of the polymers with AIBN.

Azido linker 3 was synthesized by reacting 2-(2-chloroethoxy)-ethanol with sodium azide (a) according to the literature [60]. Azido linkers 4-6 were synthesized via sequen- 
tial tosylation (b) and substitution steps with either sodium azide (a) or another linker for chain prolongment. For the azido hexaethylene glycol linker 5, diethylene glycol was used for chain prolongment as published Mahou et al. [59], and for the difunctional azido tetraethyleneglycol octyl linker 6, 1,8-octanediol was used for chain prolongment. Azidomethacrylates 7-10 were synthesized following published protocols, using methacryloyl chloride and triethylamine [61].

The functional glycoside, propargyl GlcNAc 13, was synthesized as described by Schmidt et al. [62]. N-Acetylglucosamine was used as starting material, followed by protection with acetyl groups, conversion of the peracetylated $\mathrm{N}$-acetylglucosamine into an oxazoline as glycoside donor, and further glycosidation using propargyl alcohol to $\mathrm{N}$-acetylpropargylglucosamine 13. For click functionalization, the optimized conditions reported by Schmidt et al. [62] were used, yielding the GlcNAc-functionalized monomers 11a-d. To further elucidate antimicrobial properties of the combined triazole and linker in the polymers, azido oligoethylene glycol methacrylates 7-9 were reacted under the same conditions with propargyl alcohol to their 4-hydroxymethyl-[1,2,3]-triazo-1-yl counterparts 12a-c. The 4-hydroxymethyl derivatives $\mathbf{1 2 a}-\mathbf{c}$ and the GlcNAc derivatives 11a-d were used as functional monomers directly for polymerization.

\subsection{Polymer Synthesis}

Functional GlcNAc monomers 11a-d were successfully polymerized using free radical polymerization with AIBN as radical starter (Figure 1B), followed by several purification steps with precipitation and $O$-acetyl deprotection to the functional glycosidic polymer. Functional 4-hydroxymethyl monomers 12a-c were polymerized using free radical polymerization with AIBN (Figure 1C) followed by purification and used directly because no protection groups were involved. The 4-methacryloyloxy-benzophenone 14 was synthesized according to the literature [57]. All synthesized polymers with their corresponding abbreviations are listed in Table 1.

Analysis of the polymers and the copolymer ratio between MBP 14 and functional monomers 11 or 12 was performed by ${ }^{1} \mathrm{H}$ NMR spectroscopy, followed by 2-dimensional measurements for glycosidic structure determination. The triazole proton, showing a relatively isolated singlet at $7.96 \mathrm{ppm}$, was integrated against the benzophenone aromatic protons and against the $N$-acetyl group of the glycosidic monomers 11a-d. For the 4-hydroxymethyl derivatives 12a-c without glycoside, the triazole proton at $7.96 \mathrm{ppm}$ was integrated against the benzophenone protons only. The dimethacrylamide methyl (DMAm) groups showed a broad multiplet at 2.98-2.75 ppm, which overlapped with the ethylene glycol signals of comonomers 11 and 12; therefore, the integral ratio of those signals did not match the actual copolymer ratio as shown in Figure 2. The multiplet integral was relatively constant over all three copolymers of $\mathbf{1 1} \mathbf{b}$, which had decreasing dimethacrylamide content from $90 \%$ to $70 \%$, whereas the content of $\mathbf{1 1} \mathbf{b}$ with a tetraethylene glycol linker increased from $2.5 \%$ to $25 \%$. Therefore, the DMAm content was not calculated using the integral ratios. Successful deprotection of GlcNAc-containing polymers was confirmed by disappearance of the O-acetyl groups in ${ }^{1} \mathrm{H}$ NMR after the deprotection step. For the 4-hydroxymethyl-derivative comonomers 12a-c, adjusted copolymer ratios of 1:1 MBP 14 vs. 12 were obtained. In the GlcNAc copolymer group, consisting of copolymers with comonomers 11a-d, different copolymer ratios of MBP 14 vs. 11 were obtained. Possible mechanisms are ester hydrolysis during the Zemplén deprotection step of the GlcNAc residue, because the 4-hydroxymethyl-containing polymeric counterparts did not show different copolymer ratios of the benzophenone. Interestingly, the GlcNAc-4EG copolymers showed no reduction in MBP content relative to the GlcNAc residue (Figure 2). Therefore, different reactivities of benzophenone in combination with several GlcNAc-methacrylates and oligoethylene glycol linkers are possible explanations. 


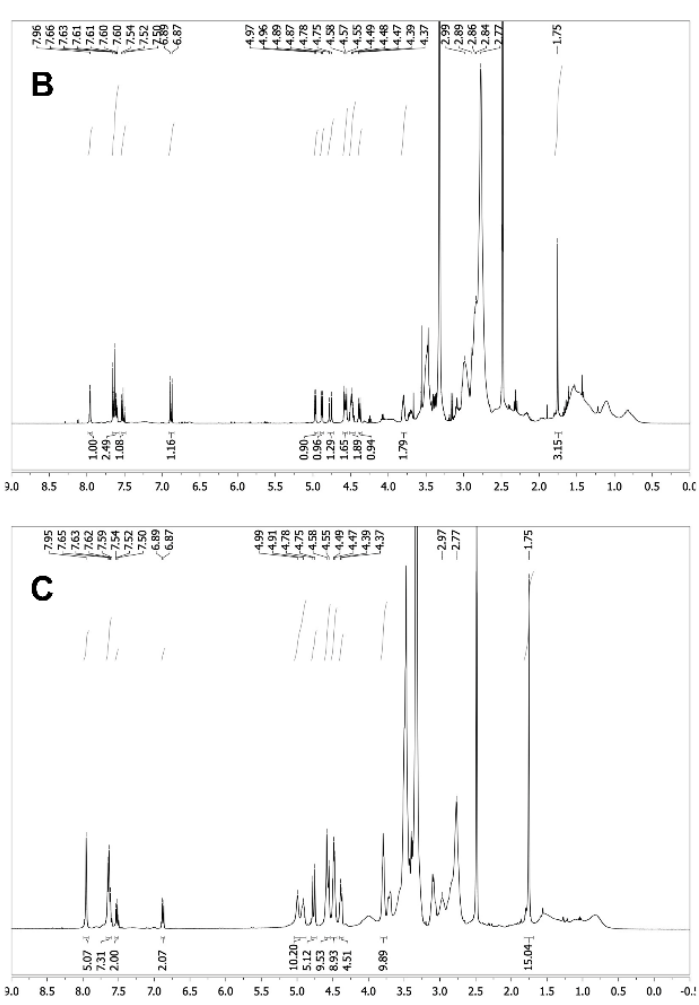

Figure 2. $1 \mathrm{H}-\mathrm{NMR}$ spectra $(600 \mathrm{MHz})$ of the $5 \%-(\mathbf{A}), 10 \%-(\mathbf{B})$ and $25 \%-(\mathbf{C})$ GlcNAc-4EG polymers (Table 1$)$. The GlcNAc and 4-hydroxymethyl triazoles proton gave a distinct singlet at $7.96 \mathrm{ppm}$, whereas the benzophenones aromatic protons gave signals from 7.66 to $6.67 \mathrm{ppm}$. Furthermore, the GlcNAc acetyl group singlet showed a signal at $1.75 \mathrm{ppm}$. The broad multiplet from 2.98 to 2.75 ppm belongs to the dimethacrylamide methyl groups. Copolymer ratio was calculated by the integral ratios of triazole-H vs. NAc vs. aromatic benzophenone-H. For the 4-hydroxymethyl comonomers, only triazole-H was integrated vs. aromatic benzophenone-H. The figure shows the increasing triazole singlet (7.96 ppm) and NAc singlet $(1.75 \mathrm{ppm})$ with increasing comonomer ratio of $\mathbf{1 1} \mathbf{b}$ vs. the aromatic protons of MBP $\mathbf{1 4}$. The dimethacrylamide multiplet between 2.98 and 2.75 ppm was relatively constant in all three spectra because it overlays the tetraethylene glycol.

Interestingly, the copolymerization of 50\% GlcNAc-4EG-methacrylate monomer resulted in ester hydrolysis of the methacrylate ester during polymerization, leading to the propargyl GlcNAc tetraethylene glycol clickamer 15 (data not shown, cf. Supplementary Materials), following the same workup procedure as for the other polymers.

\subsection{Coating of PETG Coverslips}

As the model material, polyethylene terephthalate glycol (PETG) coverslips were coated with the functional polymers. Previous studies with MBP UV crosslinker in different acrylamide scaffolds indicated that $3 \mathrm{~J} / \mathrm{cm}^{2}$ was the optimum dose of UV irradiation to obtain proper coating stability with minimum unreacted MBP left and minimum coating degradation [57]. Following the crosslinking protocol with UV light $\left(3 \mathrm{~J} / \mathrm{cm}^{2}, 254 \mathrm{~nm}\right)$ and several washing steps with $\mathrm{ddH}_{2} \mathrm{O}$ and ethanol, stable polymer coatings were obtained using the polymers listed in Table 1 . Two concentrations of polymer solutions were applied to the coverslips to obtain coatings of different thicknesses, which were investigated via IR spectroscopy. Recorded spectra of four selected coatings are shown in Figure 3. 


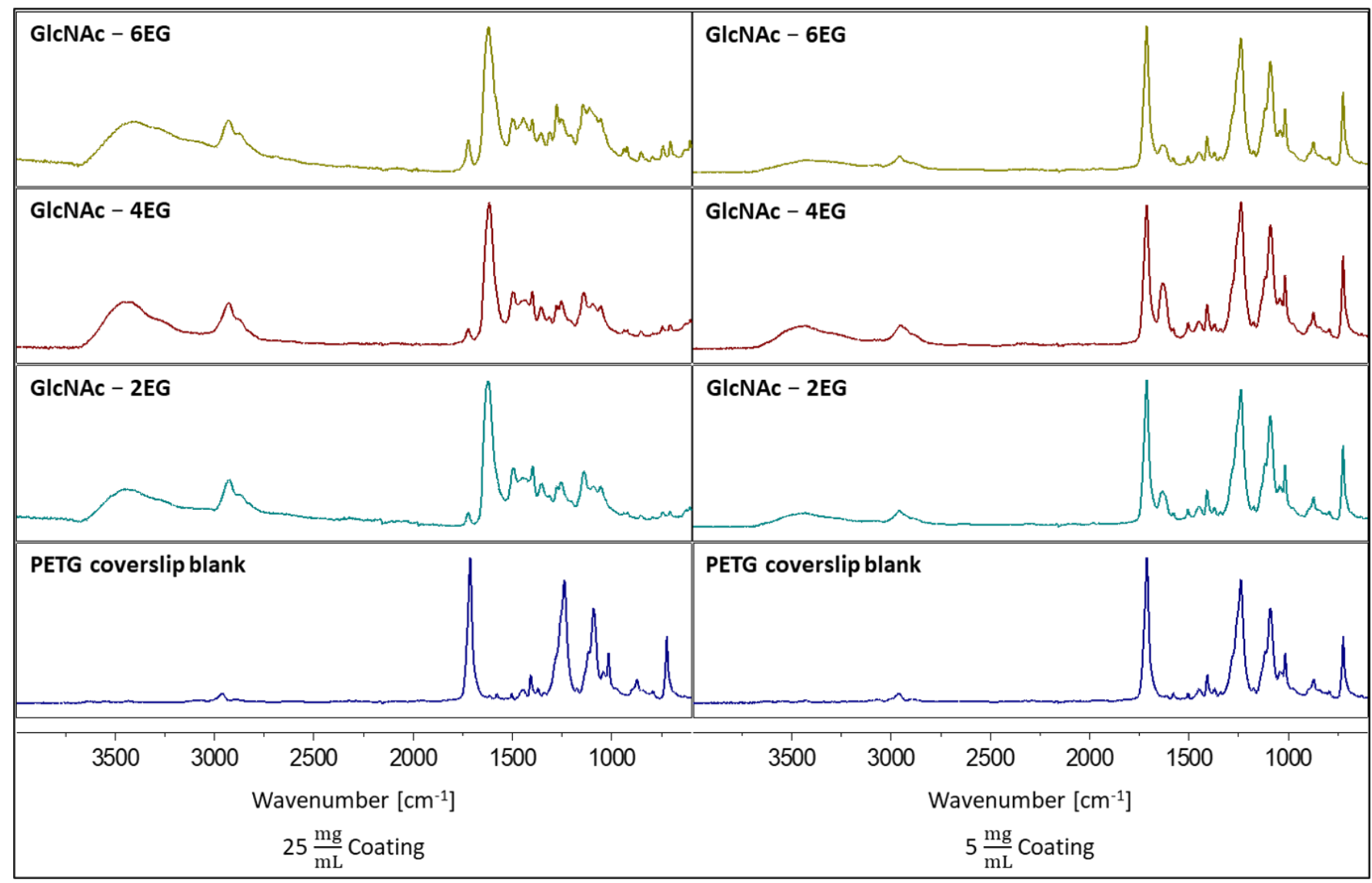

Figure 3. Recorded Fourier transform-infrared spectra of selected functional PDMAm-co-P-benzophenone-MA-co-PGlcNAc-OEG-MA coatings (Table 1) containing 5\% GlcNAc copolymer and linkers with 2, 4 and 6 ethylene glycol (EG)

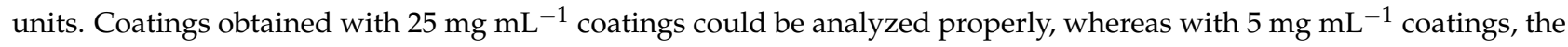
terephthalate group of the PETG was the dominant signal in the recorded IR spectra.

The dominant peak at $1713 \mathrm{~cm}^{-1}$ of the terephthalate of PETG from the coverslip blank disappeared in all polymeric coatings obtained by drop casting a $25 \mathrm{mg} / \mathrm{mL}$ solution after crosslinking, wherein the peak of the dimethacrylamide dimethyl-carboxamide group at $1621 \mathrm{~cm}^{-1}$ became visible as well as the copolymer ester groups at $1721 \mathrm{~cm}^{-1}$. The presence of the GlcNAc residue was confirmed through the presence of glycosidic $\mathrm{OH}$ groups, showing broad peaks at $3450 \mathrm{~cm}^{-1}$ and at $2925 \mathrm{~cm}^{-1}$. The stable coatings were obtained using the polymers as listed in Table 1 with the given MBP copolymer ratios. Therefore, apart from the synthesis, stable coatings using a $25 \mathrm{mg} / \mathrm{mL}$ casting solution were obtained.

In coatings obtained by casting a $5 \mathrm{mg} / \mathrm{mL}$ polymer solution, the most dominant peak in the IR spectra of the coatings was the PETG terephthalate peak at $1713 \mathrm{~cm}^{-1}$, followed by a smaller peak of the dimethacrylamide dimethyl-carboxamide group at $1621 \mathrm{~cm}^{-1}$. The copolymer ester groups at $1721 \mathrm{~cm}^{-1}$ were not visible at all compared with those of the thicker $25 \mathrm{mg} / \mathrm{mL}$ coatings, possibly being overlaid by the dominant terephthalate peak. As a result, the polymer coatings for antimicrobial studies and cytotoxicity evaluations were prepared by casting a $25 \mathrm{mg} / \mathrm{mL}$ solution to obtain an appropriate coating thickness.

\subsection{Surface Morphology}

The surface morphology of the bioactive polymer coatings 5\%-GlcNAc-6EG-PDMAm and 5\%-GlcNAc-4EG-PDMAm was investigated by SEM and AFM as shown in Figure 4. SEM images were recorded at a tilted angle of 40 degrees. For the 5\%-GlcNAc-4EGPDMAm, in the SEM image (Figure 4A), a textured surface showing small pores and a sponge-like structure can be observed. Furthermore, small particles in the size of up to 
$500 \mathrm{~nm}$ are present. The AFM surface topography (Figure 4B) confirms the topography. Similar observations can be made for the GlcNAc-6EG coating (Figure 4C,D), but showing less pore-like structures than the 5\%-GlcNAc-PDMAm coating.

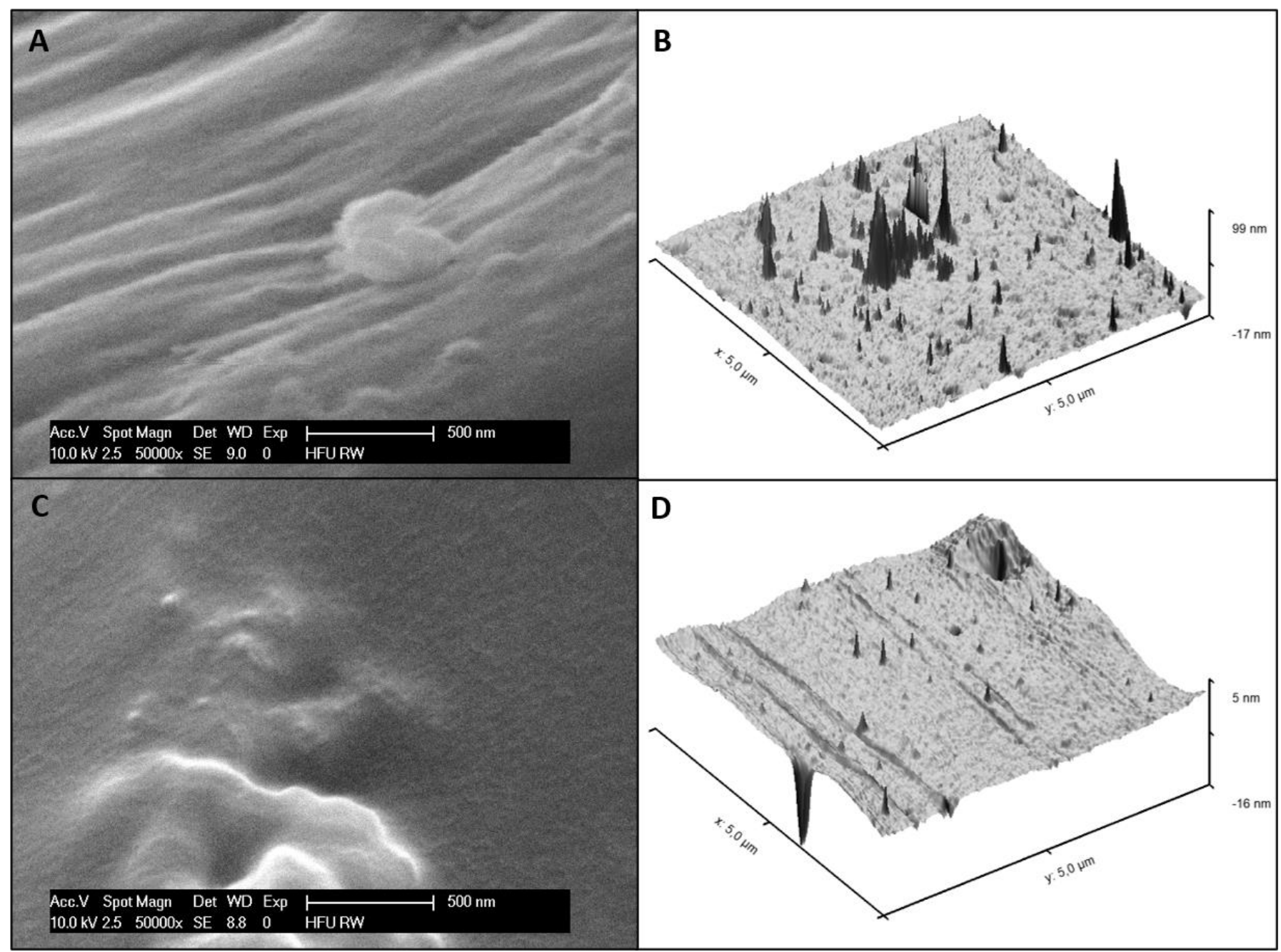

Figure 4. SEM (A,C) and AFM (B,D) images of the bioactive PDMAm coatings, 5\%-GlcNAc-4EG (A,B) and GlcNAc-6EG (C,D).

\subsection{Coating Sterilization}

Due to the sterile demands for biocompatibility testing as well as for antimicrobial activity testing against specified bacterial strains, the successful sterilization of the coating was established prior to testing. Therefore, polymer solutions were sterile filtered with a $0.2 \mu \mathrm{m}$ sterile filter and handled under sterile condition in a biosafety cabinet during coating of the corresponding surfaces, followed by crosslinking with $3 \mathrm{~J} / \mathrm{cm}^{2} \mathrm{UV}-\mathrm{C}$ light $(254 \mathrm{~nm})$. The polymer coated surfaces were then incubated for $24 \mathrm{~h}$ at $37^{\circ} \mathrm{C}$ and further $24 \mathrm{~h}$ at room temperature in LB media in order to assess the sterility by absence of bacterial growth. No bacterial growth could be observed for the coated chips under these conditions.

UV sterilization is an established method in food packing, water treatment, and surface sterilization in medical settings [67,68]. For example, according to Bak et. al. [69], a 4-log fold reduction in P. aeruginosa in catheter disinfection was obtained, using UV-C light with a dosage of $40 \mathrm{~mJ} / \mathrm{cm}^{2}$. In addition, clinical studies have shown the efficacy of UV-C light against different fungi, by using a dosage of $41.25 \mathrm{~mJ} / \mathrm{cm}^{2}$ from a commercially available disinfecting device for medical settings [70,71]. In general, for a $90 \%$ inactivation of bacterial pathogens, a UV-C dosage of $8 \mathrm{~mJ} / \mathrm{cm}^{2}$ is needed [71], whereas, for ssRNA viruses, an irradiation dose of $1.32-3.20 \mathrm{~mJ} / \mathrm{cm}^{2}$ is needed [72]. Therefore, it can be 
concluded that residing pathogens as well as possible viral contaminations are eliminated after the combination of sterile filtration and UV crosslinking of the benzophenone residue in order to form the stable coating.

\subsection{Antibacterial Activity}

The antibacterial properties of the synthesized polymers were evaluated using Escherichia coli (E. coli) as a Gram-negative model organism and multidrug-resistant Staphylococcus aureus (MRSA) as a Gram-positive model organism. These organisms were chosen as model organisms with clinical relevance for infections and biofilm formation [73]. The bacteria were cultured in high-nutrition (LB medium) and low-nutrition (PBS) environments to assess the effect of the polymers in different nutritional conditions.

In the high-nutrition environment, no effect of coatings on bacterial growth of $E$. coli and S. aureus could be observed (Figure 5A). In contrast, under low-nutrition conditions (Figure 5B), the 5\%-GlcNAc-4EG $\left(4061 \pm 2184 \mathrm{CFU} / \mathrm{cm}^{2}\right)$ and 5\%-GlcNAc-6EG $\left(22,883 \pm 5172 \mathrm{CFU} / \mathrm{cm}^{2}\right)$ modified PDMAm coatings showed a reduction in bacterial viability, compared with the untreated PETG chip $\left(63,625 \pm 13,320 \mathrm{CFU} / \mathrm{cm}^{2}\right)$ and the unmodified PDMAm coating $\left(60,009 \pm 17,207 \mathrm{CFU} / \mathrm{cm}^{2}\right)$.

\section{A) Cell viability on polymer coatings in high nutrition environment}

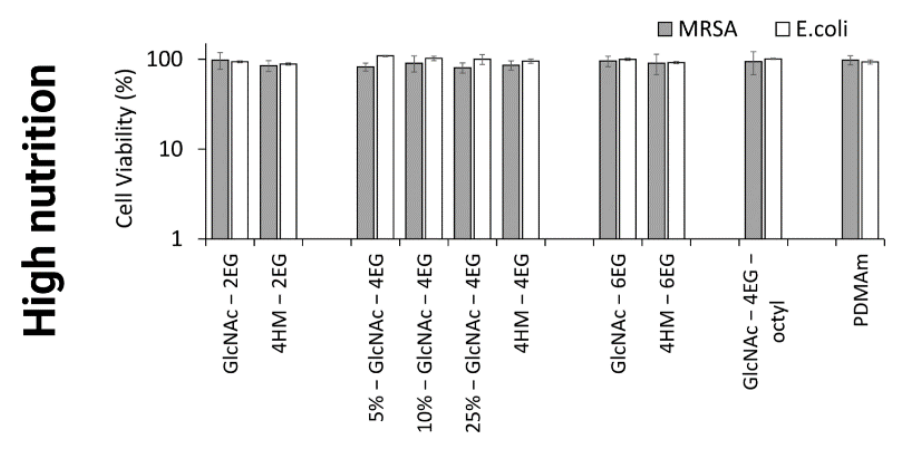

\section{B) Cell viability on polymer coatings in low nutrition environment}

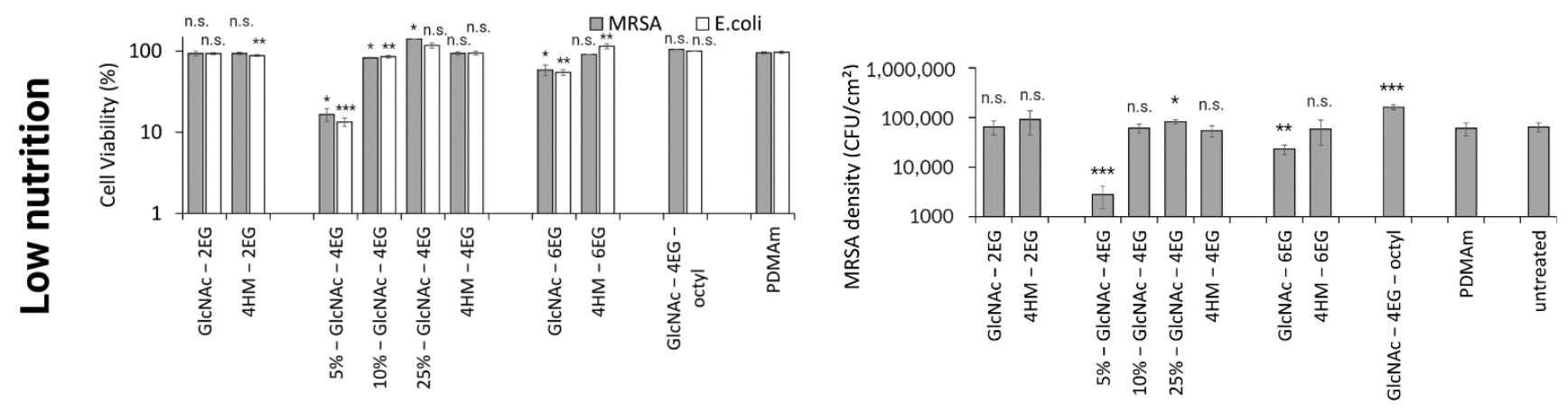

Figure 5. Antibacterial evaluation of polymer coatings in high- and low-nutrition environments. PDMAm corresponds to the unmodified acrylate coating. (A) Cell viability of Escherichia coli (E. coli) and multidrug-resistant Staphylococcus aureus (MRSA) on polymer coatings in the high-nutrition environment was assessed according to antibacterial assay (optical density, OD). Values are shown relative to that of the untreated sample. (B) Cell viability on polymer coatings in the low-nutrition environment was assessed for E. coli $(n=4)$ and MRSA $(n=2)$ according to antibacterial assay (optical density, OD, left graph) and in addition for MRSA $(n=3)$ according to the more sensitive antibacterial assay (colony-forming units, $\mathrm{CFU}$, right graph). Values are shown as mean $\pm \mathrm{SD}$. Significant changes were assessed by pairwise Student's $t$-test (n.s., not significant; $\left.{ }^{*} p<0.05 ;{ }^{* *} p<0.01 ;{ }^{* *} p<0.001\right)$. 
Both the GlcNAc-2EG modified polymer and the triazole-bearing 4-hydroxymethyl derivatives (4HM-2EG, 4HM-4EG and 4HM-6EG) did not show a considerable effect compared with unmodified PDMAm, whereas the polymers 5\%-GlcNAc-4EG and 5\%-GlcNAc-6EG showed a significant reduction in viable MRSA and E. coli in direct contact testing under low-nutrition conditions (Figure 5B). Thus, viability was reduced by $1.2 \log$ for the GlcNAc4 EG modified hydrogel and by $0.4 \log$ for the GlcNAc-6EG modified hydrogel. Higher ratios of GlcNAc-4EG copolymer in the hydrogel network did not result in a stronger antibacterial effect but resulted in bacterial viabilities similar to those of 4-hydroxymethyl functionalized coatings.

In addition to evaluating the antibacterial effect on bacterial growth, we assessed biofilm formation on the different hydrogels. The crystal violet assay for biofilm assessment showed a decrease in biofilm formation for several polymers, as shown in Figure 6A,B. In particular, the polymers 5\%-GlcNAc-4EG and 5\%-GlcNAc-6EG showed a significant decrease in biofilm formation compared with the unfunctionalized PDMAm coating. They showed a decrease in absorption at $595 \mathrm{~nm}$ for $S$. aureus of $0.46 \pm 0.07$ and $0.52 \pm 0.12$ compared with $0.89 \pm 0.14$, respectively. Biofilm formation for E. coli decreased even more: $0.23 \pm 0.07$ and $0.42 \pm 0.11$ compared with $1.06 \pm 0.11$. Higher GlcNAc-4EG copolymer content resulted in less biofilm inhibition (60-80\% biofilm content) compared with the unmodified PDMAm hydrogel. The effect was observed over a cultivation time of $72 \mathrm{~h}$ (Figure 6B) and was confirmed by EPS analysis with the phenol-sulfuric acid method described by Masuko et al. (Figure 6C) [66]. In addition, we analyzed the quantity and viability of bacteria on the polymer coatings after 24,48 and $72 \mathrm{~h}$ incubation, using live/dead staining (Figure 6D). Even though the live staining with DMAO in combination with the polymer coating resulted in high background noises, so that a low exposure time had to be selected and the intensity of the fluorescent stained bacteria was low, the overall effect of the polymer coatings could be confirmed. The quantity of bacteria was significantly lower for the polymers 5\%-GlcNAc-4EG and 5\%-GlcNAc-6EG compared to their respective controls 4HM-4EG and 4HM-6EG as can be seen in the brightfield images (Figure 6D). Furthermore, it was observed that the proportion of dead cells, especially on the 5\%-GlcNAc-4EG, was higher than on the corresponding controls and particularly on the unmodified PDMAm, where a mix of dead and alive cells was visible. Additional images taken at 24, 48 and $72 \mathrm{~h}$ are shown in the supplementary materials (Figures S2-S4).

The inhibition of biofilm formation by GlcNAc was previously observed by Sicard et al. for different E. coli strains, but not for S. aureus [47]. However, under high-nutrition conditions, there was no longer any effect on bacterial growth observed. Antibacterial effects in the low-nutrition environment were evaluated using the OD-method to identify potential candidates and additionally evaluated for MRSA using the more sensitive CFUmethod, which is more conclusive, particularly in the lower measurement range. This is attributed to the measurement procedure itself, since in the OD-method, although cells in the process of dying make up only a small part of the population, they also lead to a signal in the measurement. In contrast, only the most vital cells are taken into account in the CFU-method, as these must be able to form their own colony. The observations in the nutrient-rich environment may indicate that the polymer interferes in the metabolism of specific substrates, as studies have shown that chitosan interferes with RNA and protein synthesis [74-77]. Therefore, these substrates can no longer be used for biofilm formation or as a source of nutrients. This would explain the observed decrease in biofilm formation (high-nutrition) and bacteria viability under nutrient-poor conditions, whereas under nutrient-rich conditions, the bacteria can use other substrates as a source of nutrients, negating the growth-inhibiting effect. Another possible explanation for the lack of effect on growth under high-nutrient levels is that a higher mortality rate might have been present but was not measurable because it was obscured by significantly greater bacterial proliferation. As a result, the effect of the coatings was only observable in the low-nutrition medium, where bacterial growth was negligible and thus the increased mortality rate could be observed [78]. Nevertheless, the antibiofilm effect was observed under the nutrient-rich 
conditions, so the effect seems to be only partially dependent on the nutrient condition. The exact mechanism underlying the antibacterial and antibiofilm effect needs further elucidation [76].

\section{A) Biofilm formation on polymer coatings}

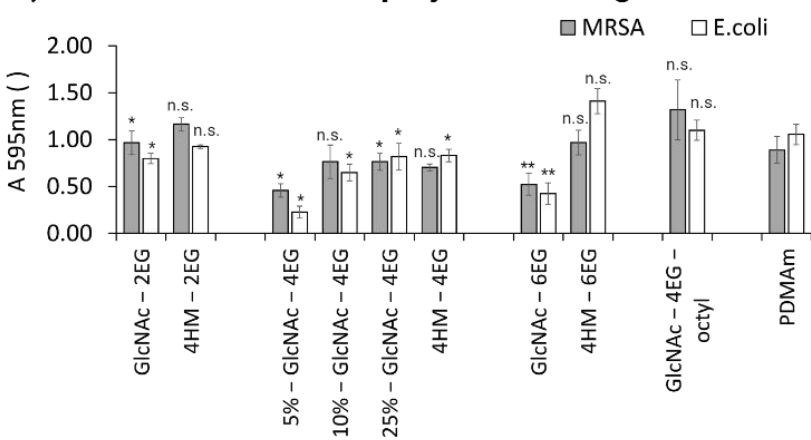

B) Biofilm formation on polymer coatings over $72 \mathrm{~h}$

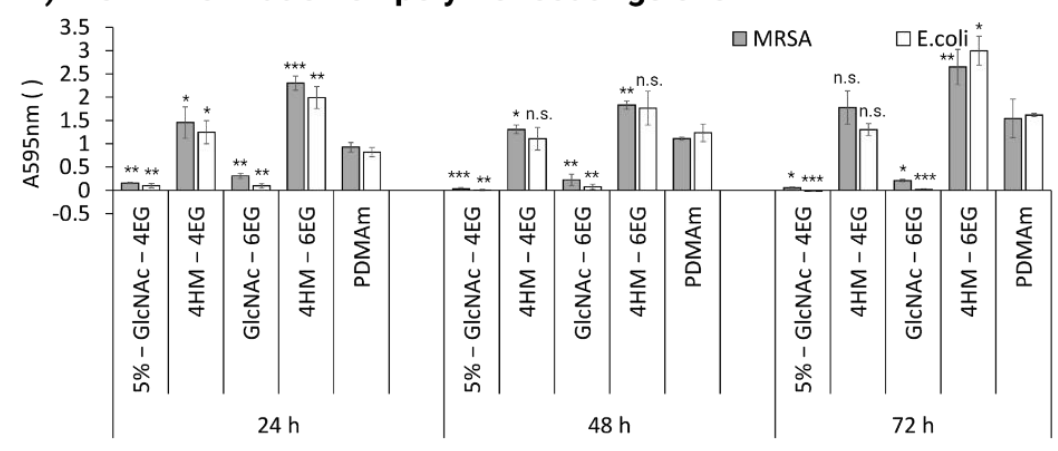

C) EPS analysis of biofilm on polymer coatings over $72 \mathrm{~h}$

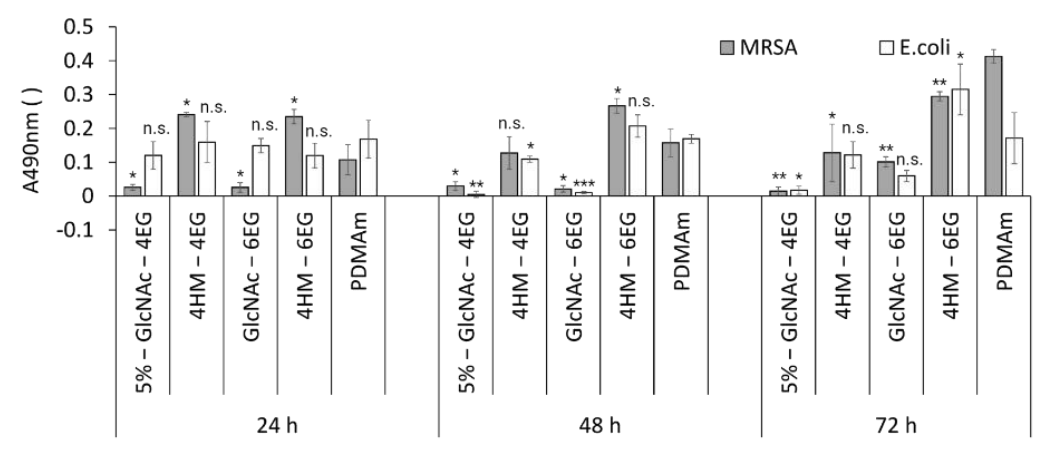

D) Live/Dead staining after $48 \mathrm{~h}$
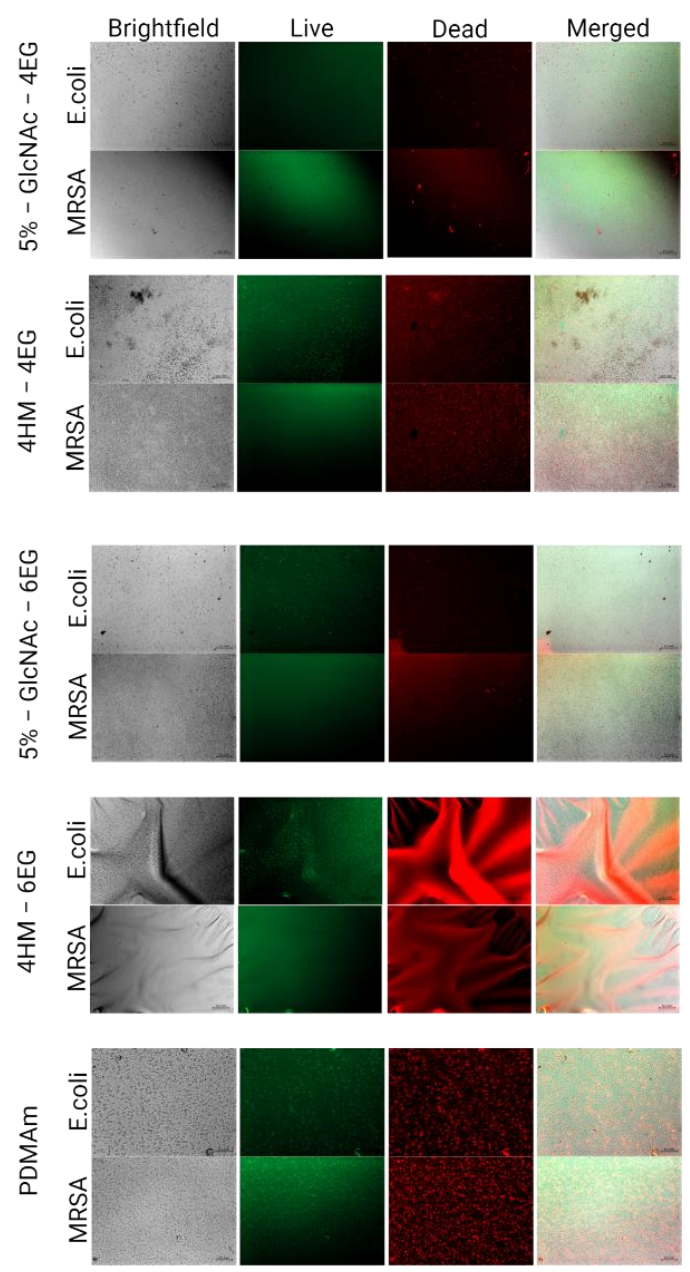

Figure 6. Evaluation of biofilm formation of polymer coatings. PDMAm corresponds to the unmodified acrylate coating. (A) Biofilm formation of E. coli and MRSA in the high-nutrition environment was assessed by crystal violet staining after $24 \mathrm{~h}$ of cultivation for all coatings as a first evaluation. (B) Biofilm formation of E. coli and MRSA in the high-nutrition environment was assessed by crystal violet staining after 24, 48 and $72 \mathrm{~h}$ of cultivation for the most active polymer coatings and their respective controls. Corresponding brightfield images are available in the supplementary materials (Figure S1) (C) Extracellular polymeric substance (EPS) analysis of formed biofilm by E. coli and MRSA in the high-nutrition environment was assessed by phenol-sulfuric acid method after 24, 48 and $72 \mathrm{~h}$ of cultivation for the most active polymer coatings and their respective controls. (D) Live/Dead staining of E. coli and MRSA in the high-nutrition environment after 24,48 and $72 \mathrm{~h}$ of cultivation for the most active polymer coatings and their respective controls. Magnification is $100 \times$; scale bar measures $0.1 \mathrm{~mm}$. Values are shown as mean $\pm \mathrm{SD}$. Significant changes were assessed by pairwise Student's $t$-test (n.s., not significant; ${ }^{*} p<0.05 ;{ }^{* *} p<0.01 ;{ }^{* * *} p<0.001$ ).

Comparison of the different synthesized coatings showed that linker length and the amount of GlcNAc are critical parameters for the antibacterial and antibiofilm functionality of the polymers. We found that the 4EG linker yielded the best results, whereas the 2EG and 6EG linkers had decreased functionality. In addition, GlcNAc content affected the antimicrobial and antibiofilm properties: the highest effect was achieved at 5\% GlcNAc and 
decreased with higher GlcNAc contents for the 4EG linker. This shows that the 4EG linker itself and therefore the length of the oligoethylene glycol brush affect biofilm formation and antimicrobial properties. The reason for this is most likely the steric arrangement of the functional groups and their distance from the sample surface. Depending on the distance, different interaction possibilities exist between the modified groups and the cell wall or membrane of the bacteria [79].

\subsection{Cytotoxicity}

A cytotoxicity evaluation of the polymeric coatings was carried out according to ISO 10993-5 standards using the extract method and the contact method. Extracts of the coatings were prepared according to ISO 10993-12 and 6\% DMSO was chosen as the positive control for cytotoxicity. Cell viability was assessed by the MTT assay.

Cell viability was measured after $72 \mathrm{~h}$ of incubation with the prepared extracts (undiluted and diluted 4-fold with medium); results are shown in Figure 7A. No notable cytotoxic effect was observed for any GlcNAc-containing copolymer in the extract test. This included the antimicrobial and antibiofilm polymer, 5\% GlcNAc-containing PDMAm hydrogel (5\%-GlcNAc-4EG), whose extracts resulted in no loss of fibroblast viability. The 4-hydroxymethyl copolymers containing a tetraethylene glycol (HM-4EG) or a hexaethylene glycol linker (HM-6EG) showed minor decreases in cell viability: a 23\% decrease for the $4 \mathrm{EG}$ linker and a $12 \%$ decrease for the $6 \mathrm{EG}$ linker. The extract of the 4-hydroxymethyl derivative with diethylene glycol linker (HM-2EG) showed no cytotoxicity.

For the direct contact test, the cell culture dish was directly coated with the polymers, followed by crosslinking with UV light, 3 washing steps with phosphate buffer, and seeding of cells onto the generated scaffolds. The observed cell viability after 24 and $48 \mathrm{~h}$, determined by MTT assay, is shown in Figure 7B. After $24 \mathrm{~h}$, cell viability was generally lower than that of the untreated cell culture dish, ranging between $60 \%$ and $80 \%$ for all polymers including the non-modified PDMAm. After $48 \mathrm{~h}$, the most functional polymer against biofilms (5\%-GlcNAc-4EG) and most other tested polymers showed only minor reductions in cell viability, within the range of biological systems. Only the GlcNAccontaining polymer with a diethylene glycol linker and the tetraethylene glycol octyl linker showed decreases in cell viability after $48 \mathrm{~h}$ (32\% and 37\%, respectively).

Furthermore, images of the cells grown directly on the polymer coatings were taken, as shown in Figure 8. Morphology of the cells grown directly on the coatings (Figure 8A-E) is altered compared to the uncoated cell culture dish (Figure $8 \mathrm{~F}$ ). It can be observed that the cell morphology is more spheroid like, which implies a lesser adhesion. Due to the experimental conditions, where the coatings were washed after 24 or $48 \mathrm{~h}$ incubation prior to addition of fresh media with MTT, an adequate adherence of the cells to the coatings should be given or else the cells would have been washed away in these steps. Thereby, it can be concluded that the L-929 Fibroblasts show adherent behavior to the coatings, albeit lower than on standard cell culture plates. According to ISO 10993:5-evaluation of cytotoxicity of biomaterials, growth inhibition of $>30 \%$ compared with an untreated control is considered indicative of cytotoxicity [80]. No polymers, except the GlcNAc2EG and GlcNAc-4EG-octyl polymers showed greater growth inhibition than 30\%, and therefore, all polymers except the GlcNAc-2EG and GlcNAc-4EG-octyl polymers can be considered noncytotoxic. 
A) Cell viability in $25 \%$ and $100 \%$ polymer-extract
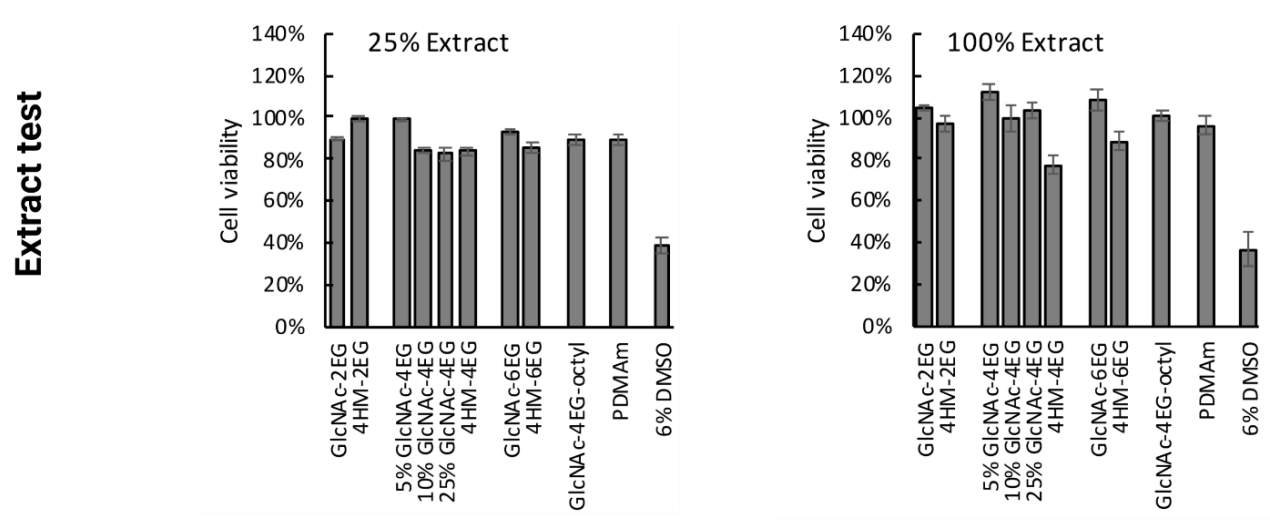

B) Cell viability in direct contact after 24 and $48 \mathrm{~h}$
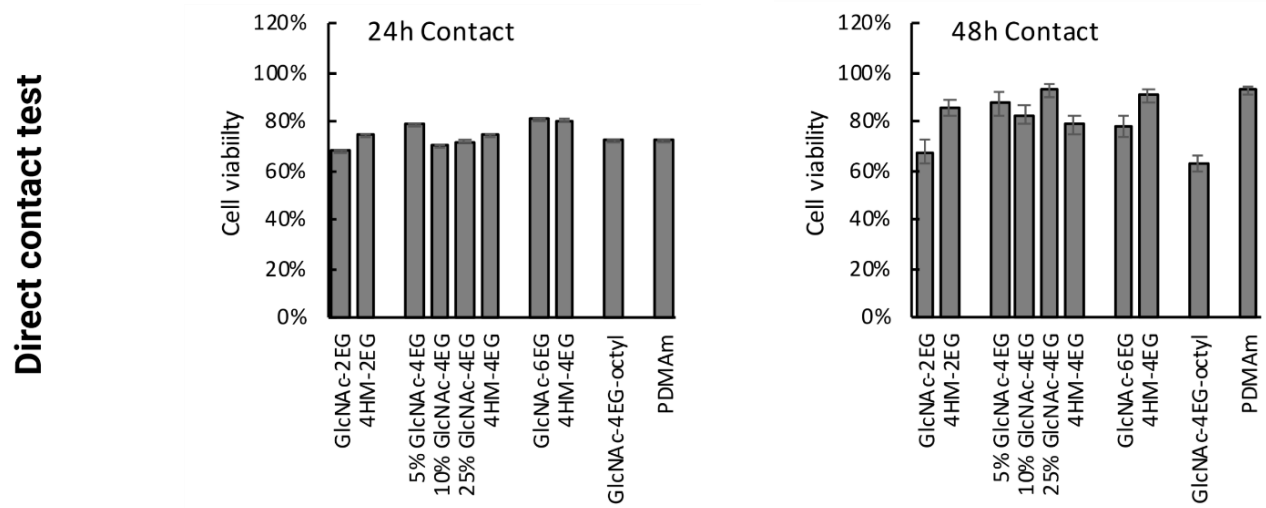

Figure 7. Cytotoxicity determination according to ISO 10993-5. (A) Cell viability measured with MTT assay after $72 \mathrm{~h}$ of incubation with $100 \%$ and $25 \%$ extracts; $6 \%$ DMSO was used as positive control for cytotoxicity. In both cases, no cytotoxicity was observed for the antimicrobial 5\%-GlcNAc-4EG polymer. (B) Cell viability in direct contact test after 24 and $48 \mathrm{~h}$, determined by MTT assay. The main functional polymer, $5 \%$-GlcNAc- $4 \mathrm{EG}$, showed no more than a $20 \%$ decrease in cell viability by the direct contact test.

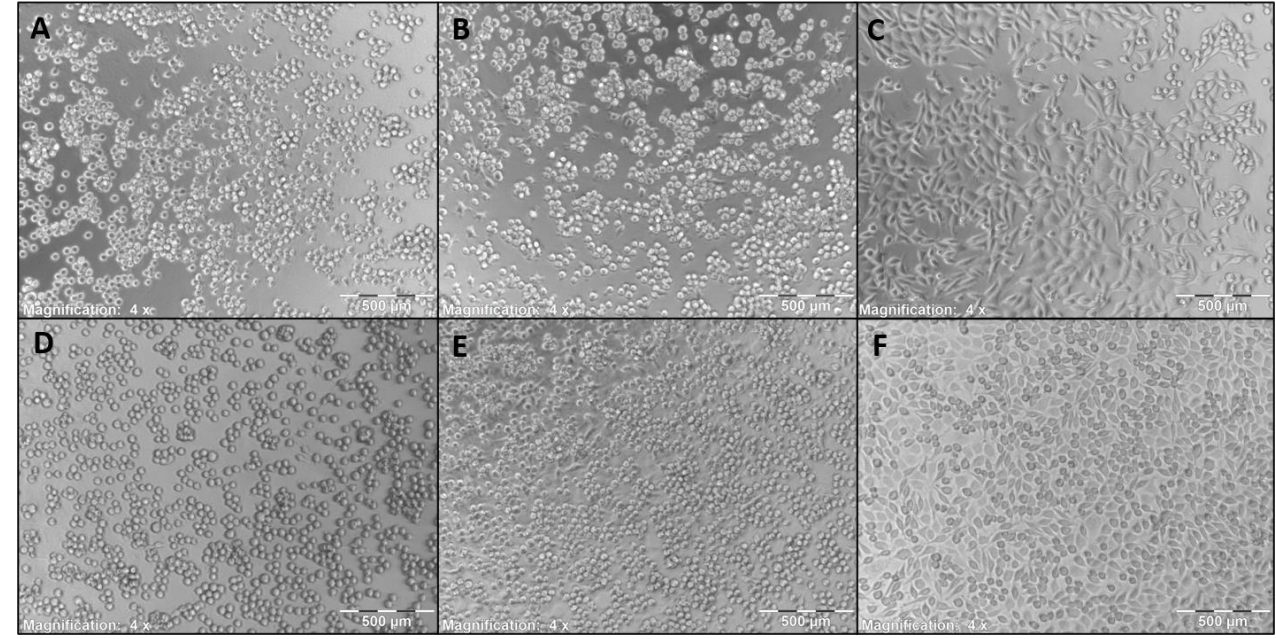

Figure 8. L-929 mouse fibroblasts grown on the coatings for $48 \mathrm{~h}$. (A) GlcNAc-2EG-PDMAm, (B) GlcNAc-4EG-PDMAm, (C) 10\%-GlcNAc-4EG-PDMAm, (D) GlcNAc-6EG-PDMAm, (E) PDMAm, (F) untreated cell culture dish. Morphology is altered to some extent, but cell viability is still given as shown via MTT test in Figure 7, in which the shown polymers show no more than $20 \%$ reduction in cell viability, so no cytotoxicity can be assumed. 


\section{Conclusions}

In summary, we demonstrated the successful synthesis of functionalized PDMAm hydrogel networks, suitable for polymer surface coating via UV-induced $\mathrm{C}-\mathrm{H}$ insertion reaction. Stable coatings were obtained using benzophenone crosslinker chemistry. A proper sterility of the surface after UV treatment for crosslinking was shown by the absence of bacterial growth in sterile medium. The functionalized coatings showed antimicrobial and antibiofilm properties, leading to a significant reduction of microbial biofilm formation on the coated surface, for both Gram-positive (S. aureus) and Gram-negative (E. coli) bacteria. We showed up to a $1.2 \log$ decrease in colony-forming units of the clinically relevant pathogen MRSA on surfaces treated with polymer coating. Non-cytotoxicity and biocompatibility toward fibroblast cells, evaluated according to ISO 10993-5 standards, was maintained. Overall, this work describes an interesting approach for decreasing bacterial adhesion to surfaces by selective functionalization with antiadhesive and antimicrobial molecules, preventing bacterial colonization and contamination of wound dressings or surgical implants. The use of such coatings can not only prevent many surgically induced infections or the formation of biofilms in chronic wounds but also help to accelerate wound healing by favoring fibroblasts.

Supplementary Materials: The following are available online at https://www.mdpi.com/article/ 10.3390/pharmaceutics13101647/s1. Figure S1: Brightfield images after crystal violet staining of biofilm formation on polymer coatings. Figure S2: Fluorescent images after Live/Dead staining of $E$. coli and MRSA in the high-nutrition environment after $24 \mathrm{~h}$ of cultivation. Figure S3: Fluorescent images after Live/Dead staining of E. coli and MRSA in the high-nutrition environment after $48 \mathrm{~h}$ of cultivation. Figure S4: Fluorescent images after Live/Dead staining of E. coli and MRSA in the high-nutrition environment after $72 \mathrm{~h}$ of cultivation.

Author Contributions: Conceptualization, H.-P.D.; data curation, M.B. and O.R.; funding acquisition, H.-P.D.; investigation, M.B., O.R., T.K. and S.J.; methodology, M.B., O.R. and S.J.; project administration, S.R.; resources, M.S.S., M.E. and H.-P.D.; supervision, S.L., R.C. and H.-P.D.; visualization, M.B. and O.R.; writing—original draft, M.B., O.R. and H.-P.D.; writing—review and editing, M.B., O.R., S.R., M.S.S., S.J., M.E., S.L., R.C. and H.-P.D. All authors have read and agreed to the published version of the manuscript.

Funding: This research was funded by Europäischer Fonds für regionale Entwicklung (EFRE) in the program "Interreg VOberrhein" (Ref: 5115/3.17), by the project "CoHMed MS-Tox Test" (FKZ: 13FH5E01IA; BMBF), and the CoHMed-project "FunktioMed" (FKZ: 13FH5I02IA; BMBF).

Data Availability Statement: The data presented in this study is available in the supplementary material.

Acknowledgments: The authors thank Oliver Podlech, CleanControlling $\mathrm{GmbH}$, for sharing the L-929 cell line and helpful advice regarding cell handling and biocompatibility tests according to ISO 10993-5, and Felix Blendinger for taking the SEM and AFM images. We are grateful to S. the R. for management of all the projects. The authors are grateful for funding of this work provided by the project "TriMaBone-Trinationale Forschungsinitiative: 3D-Druck Materialien für resorbierbare Knochen-implantate" (Europäischer Fonds für regionale Entwicklung-EFRE) in the program "Interreg VOberrhein" (Ref: 5115/3.17), by the project "CoHMed MS-Tox Test" (FKZ: 13FH5E01IA; BMBF) and the CoHMed-project "FunktioMed" (FKZ: 13FH5I02IA; BMBF)). The article processing charge was funded by the Baden-Wuerttemberg Ministry of Science, Research, and Culture and the Furtwangen University in the funding program Open Access Publishing.

Conflicts of Interest: The authors declare no conflict of interest.

\section{References}

1. Darouiche, R.O. Device-Associated Infections: A Macroproblem That Starts with Microadherence. Clin. Infect. Dis. 2001, 33, 1567-1572. [CrossRef]

2. Zhang, A.; Mu, H.; Zhang, W.; Cui, G.; Zhu, J.; Duan, J. Chitosan Coupling Makes Microbial Biofilms Susceptible to Antibiotics. Sci. Rep. 2013, 3, 1-7. [CrossRef]

3. Olivares, E.; Badel-Berchoux, S.; Provot, C.; Prévost, G.; Bernardi, T.; Jehl, F. Clinical Impact of Antibiotics for the Treatment of Pseudomonas aeruginosa Biofilm Infections. Front. Microbiol. 2020, 10, 2894. [CrossRef] 
4. Teerawattanapong, N.; Panich, P.; Kulpokin, D.; Na Ranong, S.; Kongpakwattana, K.; Saksinanon, A.; Goh, B.-H.; Lee, L.-H.; Apisarnthanarak, A.; Chaiyakunapruk, N. A Systematic Review of the Burden of Multidrug-Resistant Healthcare-Associated Infections among Intensive Care Unit Patients in Southeast Asia: The Rise of Multidrug-Resistant Acinetobacter baumannii. Infect. Control Hosp. Epidemiol. 2018, 39, 525-533. [CrossRef] [PubMed]

5. Gristina, A.G. Biomaterial-Centered Infection: Microbial Adhesion versus Tissue Integration. Science 1987, 237, 1588. [CrossRef]

6. Busscher, H.J.; van der Mei, H.C.; Subbiahdoss, G.; Jutte, P.C.; van den Dungen, J.J.A.M.; Zaat, S.A.J.; Schultz, M.J.; Grainger, D.W. Biomaterial-Associated Infection: Locating the Finish Line in the Race for the Surface. Sci. Transl. Med. 2012, 4, 153rv10. [CrossRef] [PubMed]

7. Poelstra, K.A.; Barekzi, N.A.; Rediske, A.M.; Felts, A.G.; Slunt, J.B.; Grainger, D.W. Prophylactic Treatment of Gram-Positive and Gram-Negative Abdominal Implant Infections Using Locally Delivered Polyclonal Antibodies. J. Biomed. Mater. Res. 2002, 60, 206-215. [CrossRef] [PubMed]

8. Fux, C.A.; Costerton, J.W.; Stewart, P.S.; Stoodley, P. Survival Strategies of Infectious Biofilms. Trends Microbiol. 2005, 13, 34-40. [CrossRef] [PubMed]

9. Vuong, C.; Voyich, J.M.; Fischer, E.R.; Braughton, K.R.; Whitney, A.R.; DeLeo, F.R.; Otto, M. Polysaccharide Intercellular Adhesin (PIA) Protects Staphylococcus epidermidis against Major Components of the Human Innate Immune System. Cell. Microbiol. 2004, 6, 269-275. [CrossRef] [PubMed]

10. Attinger, C.; Wolcott, R. Clinically Addressing Biofilm in Chronic Wounds. Adv. Wound Care 2012, 1, 127-132. [CrossRef]

11. Costerton, J.W.; Stewart, P.S.; Greenberg, E.P. Bacterial Biofilms: A common Cause of Persistent Infections. Science 1999, $284,1318$. [CrossRef]

12. Zimmerli, W.; Widmer, A.F.; Blatter, M.; Frei, R.; Ochsner, P.E. Role of Rifampin for Treatment of Orthopedic Implant-Related Staphylococcal Infections: A Randomized Controlled Trial. J. Am. Med. Assoc. 1998, 279, 1537-1541. [CrossRef] [PubMed]

13. Schmidmaier, G.; Lucke, M.; Wildemann, B.; Haas, N.P.; Raschke, M. Prophylaxis and Treatment of Implant-Related Infections by Antibiotic-Coated Implants: A Review. Injury 2006, 37, 105-112. [CrossRef]

14. Ghafouri, H.B.; Bagheri-Behzad, B.; Yasinzadeh, M.R.; Modirian, E.; Divsalar, D.; Farahmand, S. Prophylactic Antibiotic Therapy in Contaminated Traumatic Wounds: Two Days versus Five Days Treatment. BioImpacts 2012, 2, 33-37. [CrossRef] [PubMed]

15. De Kraker, M.E.A.; Stewardson, A.J.; Harbarth, S. Will 10 Million People Die a Year due to Antimicrobial Resistance by 2050? PLoS Med. 2016, 13, e1002184. [CrossRef] [PubMed]

16. Nations, U.; Assembly, G.; York, N.; Humphreys, G.; Fleck, F. United Nations Meeting on Antimicrobial Resistance. Bull. World Health Organ. 2016, 94, 638-639.

17. Kargupta, R.; Bok, S.; Darr, C.M.; Crist, B.D.; Gangopadhyay, K.; Gangopadhyay, S.; Sengupta, S. Coatings and Surface Modifications Imparting Antimicrobial Activity to Orthopedic Implants. Wiley Interdiscip. Rev. Nanomed. Nanobiotechnology 2014, 6, 475-495. [CrossRef]

18. Brooks, B.D.; Brooks, A.E. Therapeutic Strategies to Combat Antibiotic Resistance. Adv. Drug Deliv. Rev. 2014, 78, 14-27. [CrossRef]

19. Hebeish, A.; El-Rafie, M.H.; EL-Sheikh, M.A.; Seleem, A.A.; El-Naggar, M.E. Antimicrobial Wound Dressing and AntiInflammatory Efficacy of Silver Nanoparticles. Int. J. Biol. Macromol. 2014, 65, 509-515. [CrossRef] [PubMed]

20. Murata, H.; Koepsel, R.R.; Matyjaszewski, K.; Russell, A.J. Permanent, Non-Leaching Antibacterial Surfaces-2: How High Density Cationic Surfaces Kill Bacterial Cells. Biomaterials 2007, 28, 4870-4879. [CrossRef]

21. Tiller, J.C.; Liao, C.-J.; Lewis, K.; Klibanov, A.M. Designing Surfaces That Kill Bacteria on Contact. Proc. Natl. Acad. Sci. USA 2001, 98, 5981-5985. [CrossRef]

22. Samal, S.K.; Dash, M.; Van Vlierberghe, S.; Kaplan, D.L.; Chiellini, E.; van Blitterswijk, C.; Moroni, L.; Dubruel, P. Cationic Polymers and Their Therapeutic Potential. Chem. Soc. Rev. 2012, 41, 7147. [CrossRef]

23. Huang, J.; Murata, H.; Koepsel, R.R.; Russell, A.J.; Matyjaszewski, K. Antibacterial Polypropylene via Surface-Initiated Atom Transfer Radical Polymerization. Biomacromolecules 2007, 8, 1396-1399. [CrossRef]

24. Lee, S.B.; Koepsel, R.R.; Morley, S.W.; Matyjaszewski, K.; Sun, Y.; Russell, A.J. Permanent, Nonleaching Antibacterial Surfaces, 1. Synthesis by Atom Transfer Radical Polymerization. Biomacromolecules 2004, 5, 877-882. [CrossRef] [PubMed]

25. Madkour, A.E.; Dabkowski, J.M.; Nüsslein, K.; Tew, G.N. Fast Disinfecting Antimicrobial Surfaces. Langmuir 2009, 25, $1060-1067$. [CrossRef] [PubMed]

26. Yang, L.; Weiss, T.M.; Lehrer, R.I.; Huang, H.W. Crystallization of Antimicrobial Pores in Membranes: Magainin and Protegrin. Biophys. J. 2000, 79, 2002-2009. [CrossRef]

27. Shai, Y. Mechanism of the Binding, Insertion and Destabilization of Phospholipid Bilayer Membranes by $\alpha$-Helical Antimicrobial and Cell Non-Selective Membrane-Lytic Peptides. Biochim. Biophys. Acta-Biomembr. 1999, 1462, 55-70. [CrossRef]

28. Matsuzaki, K. Why and How are Peptide-Lipid Interactions Utilized for Self-Defense? Magainins and Tachyplesins as Archetypes. Biochim. Biophys. Acta-Biomembr. 1999, 1462, 1-10. [CrossRef]

29. Milović, N.M.; Wang, J.; Lewis, K.; Klibanov, A.M. Immobilized N-Alkylated Polyethylenimine Avidly Kills Bacteria by Rupturing Cell Membranes with No Resistance Developed. Biotechnol. Bioeng. 2005, 90, 715-722. [CrossRef]

30. Lin, J.; Tiller, J.C.; Lee, S.B.; Lewis, K.; Klibanov, A.M. Insights into Bactericidal Action of Surface-Attached Poly(Vinyl-NHexylpyridinium) Chains. Biotechnol. Lett. 2002, 24, 801-805. [CrossRef] 
31. Lin, J.; Murthy, S.K.; Olsen, B.D.; Gleason, K.K.; Klibanov, A.M. Making Thin Polymeric Materials, Including Fabrics, Microbicidal and Also Water-Repellent. Biotechnol. Lett. 2003, 25, 1661-1665. [CrossRef] [PubMed]

32. Ikeda, T.; Hirayama, H.; Yamaguchi, H.; Tazuke, S.; Watanabe, M. Polycationic Biocides with Pendant Active Groups: Molecular Weight Dependence of Antibacterial Activity. Antimicrob. Agents Chemother. 1986, 30, 132-136. [CrossRef]

33. Ikeda, T.; Yamaguchi, H.; Tazuke, S. New Polymeric Biocides: Synthesis and Antibacterial Activities of Polycations with Pendant Biguanide Groups. Antimicrob. Agents Chemother. 1984, 26, 139-144. [CrossRef] [PubMed]

34. Isquith, A.J.; Abbott, E.A.; Walters, P.A. Surface-Bonded Antimicrobial Activity of an Organosilicon Quaternary Ammonium Chloride. Appl. Microbiol. 1972, 24, 859-863. [CrossRef]

35. Luz, G.M.; Boesel, L.; Campo, A.D.; Mano, J.F. Micropatterning of Bioactive Glass Nanoparticles on Chitosan Membranes for Spatial Controlled Biomineralization. Langmuir 2012, 28, 6970-6977. [CrossRef] [PubMed]

36. Wang, Y.; Shi, R.; Gong, P.; Li, J.; Li, J.; Ao, D.; Wang, P.; Yang, Y.; Man, Y.; Qu, Y. Bioelectric Effect of a Chitosan Bioelectret Membrane on Bone Regeneration in Rabbit Cranial Defects. J. Bioact. Compat. Polym. 2012, 27, 122-132. [CrossRef]

37. Kim, I.-Y.; Seo, S.-J.; Moon, H.-S.; Yoo, M.-K.; Park, I.-Y.; Kim, B.-C.; Cho, C.-S. Chitosan and its Derivatives for Tissue Engineering Applications. Biotechnol. Adv. 2008, 26, 1-21. [CrossRef]

38. Sivashankari, P.R.; Prabaharan, M. Prospects of Chitosan-Based Scaffolds for Growth Factor Release in Tissue Engineering. Int. J. Biol. Macromol. 2016, 93, 1382-1389. [CrossRef]

39. Liu, Z.; Wang, H.; Wang, Y.; Lin, Q.; Yao, A.; Cao, F.; Li, D.; Zhou, J.; Duan, C.; Du, Z.; et al. The Influence of Chitosan Hydrogel on Stem Cell Engraftment, Survival and Homing in the Ischemic Myocardial Microenvironment. Biomaterials 2012, 33, $3093-3106$. [CrossRef]

40. Shi, W.; Nie, D.; Jin, G.; Chen, W.; Xia, L.; Wu, X.; Su, X.; Xu, X.; Ni, L.; Zhang, X.; et al. BDNF Blended Chitosan Scaffolds for Human Umbilical Cord MSC Transplants in Traumatic Brain Injury Therapy. Biomaterials 2012, 33, 3119-3126. [CrossRef]

41. Jayakumar, R.; Prabaharan, M.; Sudheesh Kumar, P.T.; Nair, S.V.; Tamura, H. Biomaterials Based on Chitin and Chitosan in Wound Dressing Applications. Biotechnol. Adv. 2011, 29, 322-337. [CrossRef]

42. Jayakumar, R.; Prabaharan, M.; Nair, S.V.; Tokura, S.; Tamura, H.; Selvamurugan, N. Novel Carboxymethyl Derivatives of Chitin and Chitosan Materials and Their Biomedical Applications. Prog. Mater. Sci. 2010, 55, 675-709. [CrossRef]

43. Helander, I.M.; Nurmiaho-Lassila, E.L.; Ahvenainen, R.; Rhoades, J.; Roller, S. Chitosan Disrupts the Barrier Properties of the Outer Membrane of Gram-Negative Bacteria. Int. J. Food Microbiol. 2001, 71, 235-244. [CrossRef]

44. Je, J.Y.; Kim, S.K. Chitosan Derivatives Killed Bacteria by Disrupting the Outer and Inner Membrane. J. Agric. Food Chem. 2006, 54, 6629-6633. [CrossRef] [PubMed]

45. Divya, K.; Vijayan, S.; George, T.K.; Jisha, M.S. Antimicrobial Properties of Chitosan Nanoparticles: Mode of Action and Factors Affecting Activity. Fibers Polym. 2017, 18, 221-230. [CrossRef]

46. Izano, E.A.; Sadovskaya, I.; Vinogradov, E.; Mulks, M.H.; Velliyagounder, K.; Ragunath, C.; Kher, W.B.; Ramasubbu, N.; Jabbouri, S.; Perry, M.B.; et al. Poly-N-Acetylglucosamine Mediates Biofilm Formation and Antibiotic Resistance in Actinobacillus pleuropneumoniae. Microb. Pathog. 2007, 43, 1-9. [CrossRef] [PubMed]

47. Sicard, J.F.; Vogeleer, P.; Le Bihan, G.; Rodriguez Olivera, Y.; Beaudry, F.; Jacques, M.; Harel, J. N-Acetyl-Glucosamine Influences the Biofilm Formation of Escherichia coli. Gut Pathog. 2018, 10, 26. [CrossRef] [PubMed]

48. Blagodatskikh, I.V.; Kulikov, S.N.; Vyshivannaya, O.V.; Bezrodnykh, E.A.; Yamskov, I.A.; Tikhonov, V.E. Influence of Glucosamine on Oligochitosan Solubility and Antibacterial Activity. Carbohydr. Res. 2013, 381, 28-32. [CrossRef]

49. Dheer, D.; Singh, V.; Shankar, R. Medicinal Attributes of 1,2,3-Triazoles: Current Developments. Bioorg. Chem. 2017, 71, 30-54. [CrossRef]

50. Kolb, H.C.; Finn, M.G.; Sharpless, K.B. Click Chemistry: Diverse Chemical Function from a Few Good Reactions. Angew. Chemie Int. Ed. 2001, 40, 2004-2021. [CrossRef]

51. Kolb, H.C.; Sharpless, K.B. The Growing Impact of Click Chemistry on Drug Discovery. Drug Discov. Today 2003, 8, 1128-1137. [CrossRef]

52. Wang, L.; Chen, J.; Shi, L.; Shi, Z.; Ren, L.; Wang, Y. The Promotion of Antimicrobial Activity on Silicon Substrates Using a "click" Immobilized Short Peptide. Chem. Commun. 2014, 50, 975-977. [CrossRef] [PubMed]

53. Głowacka, I.E.; Grzonkowski, P.; Lisiecki, P.; Kalinowski, Ł.; Piotrowska, D.G. Synthesis and Antimicrobial Activity of Novel 1,2,3-Triazole-Conjugates of Quinazolin-4-Ones. Arch. Pharm. 2019, 352, 1800302. [CrossRef] [PubMed]

54. Petrova, K.T.; Potewar, T.M.; Correia-Da-Silva, P.; Barros, M.T.; Calhelha, R.C.; Ćiric, A.; Soković, M.; Ferreira, I.C.F.R. Antimicrobial and Cytotoxic Activities of 1,2,3-Triazole-Sucrose Derivatives. Carbohydr. Res. 2015, 417, 66-71. [CrossRef] [PubMed]

55. Holla, B.S.; Mahalinga, M.; Karthikeyan, M.S.; Poojary, B.; Akberali, P.M.; Kumari, N.S. Synthesis, Characterization and Antimicrobial Activity of Some Substituted 1,2,3-Triazoles. Eur. J. Med. Chem. 2005, 40, 1173-1178. [CrossRef]

56. Abdel-Wahab, F.B.; Mohamed, H.A.; Awad, E.A.G. Synthesis and Biological Activity of Some New 1,2,3-Triazole Hydrazone Derivatives. Eur. Chem. Bull. 2015, 4, 106-109. [CrossRef]

57. Pandiyarajan, C.K.; Prucker, O.; Zieger, B.; Rühe, J. Influence of the Molecular Structure of Surface-Attached Poly(N -alkyl Acrylamide) Coatings on the Interaction of Surfaces with Proteins, Cells and Blood Platelets. Macromol. Biosci. 2013, 13, 873-884. [CrossRef]

58. Prucker, O.; Brandstetter, T.; Rühe, J. Surface-Attached Hydrogel Coatings via C,H-Insertion Crosslinking for Biomedical and Bioanalytical Applications (Review). Biointerphases 2018, 13, 010801. [CrossRef] 
59. Mahou, R.; Wandrey, C. Versatile Route to Synthesize Heterobifunctional Poly(Ethylene Glycol) of Variable Functionality for Subsequent Pegylation. Polymers 2012, 4, 561-589. [CrossRef]

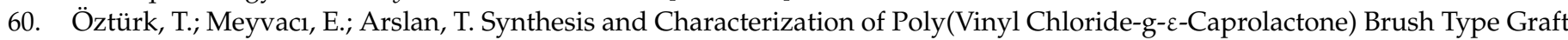
Copolymers by Ring-Opening Polymerization and "Click" Chemistry. J. Macromol. Sci. Part. A 2020, 57, 171-180. [CrossRef]

61. Sumerlin, B.S.; Tsarevsky, N.V.; Louche, G.; Lee, R.Y.; Matyjaszewski, K. Highly Efficient “Click” Functionalization of Poly(3azidopropyl methacrylate) Prepared by ATRP. Macromolecules 2005, 38, 7540-7545. [CrossRef]

62. Schmidt, M.S.; Leitner, K.; Welter, M.; Wurmthaler, L.A.; Ringwald, M. Carbohydrate-Based Cu(I) Stabilizing Ligands and Their Use in the Synthesis of Carbohydrate-Ferrocene Conjugates. Carbohydr. Res. 2014, 387, 42-45. [CrossRef] [PubMed]

63. Waldvogel, S.R. Zemplén Deacetylation. In Comprehensive Organic Name Reactions and Reagents; John Wiley \& Sons, Inc.: Hoboken, NJ, USA, 2010; Volume 2010, p. 892.

64. 87: Biological Reactivity Tests, in Vitro. In The United States Pharmacopeia-The National Formulary; Pharmacopeial Convention, Inc.: Rockville, MD, USA, 1979; Volume 35, pp. 92-94.

65. Japan Food Research Laboratories. Measurement of Antibacterial Activity on Plastics and Other Non-Porous Surfaces; ISO: London, UK, 2011; pp. 1-24.

66. Masuko, T.; Minami, A.; Iwasaki, N.; Majima, T.; Nishimura, S.I.; Lee, Y.C. Carbohydrate Analysis by a Phenol-Sulfuric Acid Method in Microplate Format. Anal. Biochem. 2005, 339, 69-72. [CrossRef] [PubMed]

67. Kowalski, W. Ultraviolet Germicidal Irradiation Handbook; Springer: Berlin/Heidelberg, Germany, 2009 ; ISBN 9783642019982.

68. Cutler, T.D.; Zimmerman, J.J. Ultraviolet Irradiation and the Mechanisms Underlying its Inactivation of Infectious Agents. Anim. Health Res. Rev. 2011, 12, 15-23. [CrossRef]

69. Bak, J.; Begovic, T. A Prototype Catheter Designed for Ultraviolet C Disinfection. J. Hosp. Infect. 2013, 84, 173-177. [CrossRef]

70. Yang, J.-H.; Wu, U.-I.; Tai, H.-M.; Sheng, W.-H. Effectiveness of an Ultraviolet-C Disinfection System for Reduction of HealthcareAssociated Pathogens. J. Microbiol. Immunol. Infect. 2019, 52, 487-493. [CrossRef] [PubMed]

71. Gora, S.L.; Rauch, K.D.; Ontiveros, C.C.; Stoddart, A.K.; Gagnon, G.A. Inactivation of Biofilm-Bound Pseudomonas Aeruginosa Bacteria Using UVC Light Emitting Diodes (UVC LEDs). Water Res. 2019, 151, 193-202. [CrossRef]

72. Tseng, C.-C.; Li, C.-S. Inactivation of Viruses on Surfaces by Ultraviolet Germicidal Irradiation. J. Occup. Environ. Hyg. 2007, 4, 400-405. [CrossRef]

73. Donlan, R.M. Biofilms and Device-Associated Infections. In Proceedings of the Emerging Infectious Diseases; Centers for Disease Control and Prevention (CDC): Atlanta, GA, USA, 2001; Volume 7, pp. 277-281.

74. Liu, X.F.; Guan, Y.L.; Yang, D.Z.; Li, Z.; Yao, K. De Antibacterial Action of Chitosan and Carboxymethylated Chitosan. J. Appl. Polym. Sci. 2001, 79, 1324-1335. [CrossRef]

75. LI, M.; CHEN, C.; XIA, X.; GARBA, B.; SHANG, L.; WANG, Y. Proteomic Analysis of the Inhibitory Effect of Chitosan on Penicillium expansum. Food Sci. Technol. 2020, 40, 250-257. [CrossRef]

76. Khan, F.; Pham, D.T.N.; Oloketuyi, S.F.; Manivasagan, P.; Oh, J.; Kim, Y.-M. Chitosan and Their Derivatives: Antibiofilm Drugs against Pathogenic Bacteria. Colloids Surf. B Biointerfaces 2020, 185, 110627. [CrossRef] [PubMed]

77. Tantala, J.; Thumanu, K.; Rachtanapun, C. An Assessment of Antibacterial Mode of Action of Chitosan on Listeria innocua Cells Using Real-Time HATR-FTIR Spectroscopy. Int. J. Biol. Macromol. 2019, 135, 386-393. [CrossRef] [PubMed]

78. Andres, Y.; Giraud, L.; Gerente, C.; Le Cloirec, P. Antibacterial Effects of Chitosan Powder: Mechanisms of Action. Environ. Technol. 2007, 28, 1357-1363. [CrossRef] [PubMed]

79. Liu, H.; Du, Y.; Wang, X.; Sun, L. Chitosan Kills Bacteria through Cell Membrane Damage. Int. J. Food Microbiol. 2004, 95, 147-155. [CrossRef] [PubMed]

80. ISO. Biological Evaluation of Medical Devices-Part. 5: Tests for In Vitro Cytotoxicity; ISO: London, UK, 2009. 